\title{
ESTUDO SISTEMÁTICO DAS ESPÉCIES BRASILEIRAS DO GÊNERO Xiphinema Cobb, 1913 (NEMATA, LONGIDORIDAE)
}

LUIZ CARLOS C. BARBOSA FERRAZ

Engenheiro-Agrônomo

Orientador: Dr. Luiz Gonzaga E. Lordello

Dissertação apresentada à Escola Superior de Agriculłura "Luiz de Queiroz", da Universidade de São Paulo, para obtenção do Título de Mestre em Entomologia.

PIRACICA B A

Estado de São Paulo - Brasil

Julho 1977 
Aos

meus queridos pais

DED I C O

\section{$\bar{A}$}

sobrinha Valēria

OFEREC O 


\section{$\underline{A} \underline{G} \underline{R} \underline{A} \underline{D} \underline{C} \underline{I} \underline{M} \underline{E} \underline{N} \underline{T} \underline{O} \underline{S}$}

Ao Prof. Dr. Luiz Gonzaga E. Lordello, pela segura orientação, constante estímulo e grande contribuição à minha formação profissional.

Ao Prof. Dr. Ailton Rocha Monteiro, pela amizade, apoio e inestimável colaboração durante o desenvolvimento deste trabalho.

Ao Dr. Charles W. Laughlin, pelas sugestöes apresentadas e ensinamentos recebidos.

Aos Dr. Chaw S. Huang, Dr. Ravi D. Sharma, M.S. Marineide M. de Menconça, M.S. Antonio Carlos Zem, Engঃ-Agro Rubens R. A. Lordello e Engo-Agro Malta de Queiroz Karan, pelo auxílio na coleta das amostras.

Ao Sr. Sérgio A. Françoso, pela amizade e valiosa colaboração na montagem das lâminas.

Aos Colegas e Funcionärios do Departamento de Defesa Fitossa nitäria da Faculdade de Ciências Agrárias e Veterinárias de Jaboticabal, pelo apoio recebido.

E a todas as pessoas que, direta ou indiretamente, contribuiram à realização deste trabalho. 
$\underline{I} \underline{N} \underline{\underline{I}} \underline{\subseteq} \underline{E}$

Påg.

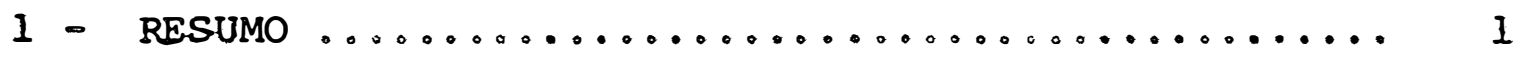

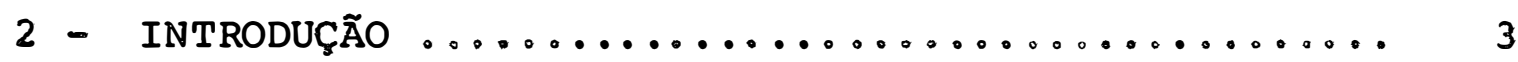

3 - MATERIAIS E MEtTOdOS ....................... 5

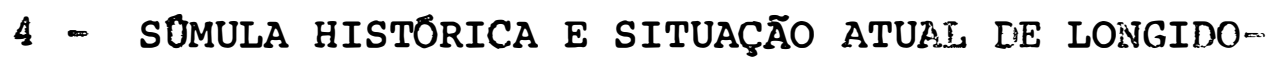
RIDAE ............................ 10

5 - HISTORICO DA FAMILIA LONGIDORIDAE WO BRASIL ..... 13

6 - SÖMULA MORFOLÓGICA DA FAMILIA LONGIDORIDAE ....... 17

7 - IMPORTÂNCIA AGRICOLA DOS NEMATÓTIDES DA FAMILIA

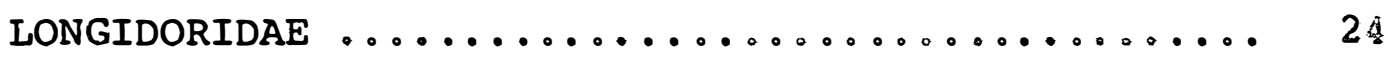

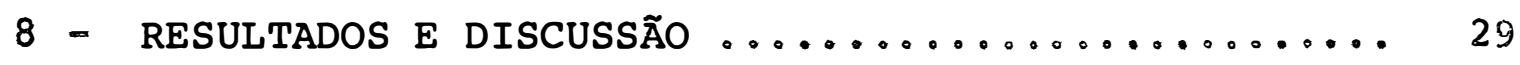

9 - CONCLUSÕES ................................ 59

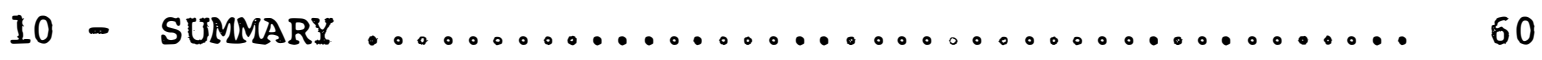

11 - LITERATURA CITADA ...................... 62

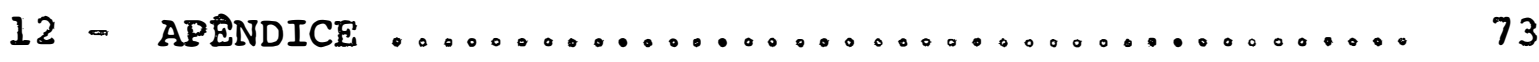


1 - RESUMO

O presente trabalho foi desenvolvido com o objetivo de contribuir ao conhecimento dos nematöides do gènero Xiphine ma Cobb, 1913 que ocorrem no Brasil.

A revisão da literatura possibilitou a elaboração de uma sümula histórlca da familia Longidoridae, assim como de $\underline{u}$ ma lista de pesquisas realizadas em nosso pals, relativas aos gêneros a ela pertencentes.

A importância agrícola dos nematöides da familia Longidoridae foi ressaltada, relatando-se os principais estudos desenvolvidos no sentido de comprovar os danos diretos que causam às plantas cultivadas, bem como sua ativa participação na transmissão de viroses.

Uma súmula morfológica foi apresentada, reunindo as características de maior interesse sistemático e importantes 
à identificação das espécies.

Foram estudas amostras de solo e rafzes de diversas culturas, plantas daninhas e vegetação natural, oriundas dos Estados do Acre, Bahia, Ceará, Goiás, Minas Gerais, Parafba, Paraná, Piaul e São Paulo, além do Território do Amapá. Nove espécies de Xiphinema foram determinadas, constituindo uma delas nova referência para o Brasil e sendo uma outra, nova à Ciência. As seguintes espécies foram identifí cadas ao curso do estudo: Xiphinema americanum Cobb, 1913: $X$. attorodorum Luc, 1961; X. brasiliense Lordello, 1951; X. brevicolle Lordello \& Costa, 1961; X. elongatum Sch. Stek. \& Teun., 1938; X. Krugi Lordel10, 1955; X. sacchari n. sp.; X. setariae Luc, 1958; X. surinamense Loof \& Maas, 1972. X. basiri Siddiqi, 1959 e X. ensiculiferum (Cobb, 1893) Thorne, 1937, embora conhecidas no Brasil, não foram observadas no presente trabalino.

0 autor propõe que $X$. paulistanum Carvalho, 1965 seja considerada "species inquirenda".

Com base em estudo da morfologia e valores obtidos da mensuração dos exemplares examinados, são apresentados comentários sobre as variações verificadas em cada espécie e discutidas diversas proposiçães de sinonimia.

Uma chave auxiliar foi elaborada para facilitar a identificação das espécies de Xiphinema referidas para o nosso Pais. 


\section{2 - INTRODUÇAO}

A família Longidoridae, que compreende quatro gêne ros, encontra-se entre os grupos de nematóides mais intensiva mente estudados. Seus representantes constituem importantes parasitos de inümeras plantas cultivadas, provocando o aparecimento de sintomas como nanismo, cloroses, necroses, galhas, redução do sistema radicular etc.. Algumas espëcies podem, ainda, atuar como eficientes agentes transmissores de viroses. Em nosso Pafs, as referênclas pertinentes à família dizem respeito, principalmente, ao gênero Xiphinema, incluindo-se descriçöes de algumas espëcles comprovadamente fitopara sitas. Contudo, em vista do elevado número de espécies que a literatura estrangeira atualmente registra, verifica-se que mesmo o acervo de estudos nacionais relativos a este gênero mostra-se, ainda, reduzido e insuficiente. 
o presente trabalho teve por objetivo, portanto, ofe recer uma contribuição ao conhecimento das espécies do gênero Xiphinema que ocorrem no Brasil, incluindo um estudo sobre a morfologia das mesmas e observações relativas tanto a sua dis tribuição geográfica como às plantas hospedeiras mais frequen tes. 
3 - MATERIAIS E METODOS

A família Longidoridae compreende nematóides tipica mente ectoparasitos. Em vista disso, a maior parte das amos tras utilizadas neste trabalho consistiu de solo coletado na região da rizosfera das plantas, segundo recomendações de STEINER (1951) e LORDELLO (1953). Amostras de raizes também constituiram material a partir do qual exemplares foram obtidos, embora o nümero de nematóides fosse menor neste caso. As amostras provieram de vários municípios paulistas, além de municípios dos Estados do Acre, Bahia, Ceará, Goiás, Minas Gerais. Paraíba, Piaul e do Território do Amapá.

As plantas, das quais obtivemos material para estudo, foram as seguintes:

Anileira

- Indigofera truxilZensis HBK - Leguminosae

Bananeira

- Musa sp. - Musaceae 


\begin{tabular}{|c|c|}
\hline Cafeeiro & - Coffea arabica L. - Rubiaceae \\
\hline Cajueiro & - Anacardirm occidentale L. - Anacardiaceae \\
\hline Cana-de-açúcar & - Sacchamon officinarm L. - Gramineae \\
\hline Carrapichinho & - Altemanthera brasiliana (L.) Kuntze - Amaranthaceae \\
\hline Caruru-de-pomba & - Phytolacca thyrsiflora L. - Phytolaccaceae \\
\hline Cebola & - AlZizon cepa L. - Liliaceae \\
\hline Citros & - Citmus sp. - Rutaceae \\
\hline Crotalaria & - Crotalaria Zauceolata Mey. - Legrominosae \\
\hline Fedegoso & - Cassia occidentalis L. - Leguminosae \\
\hline Feijoeiro & - Phaseolus vulgaris L. - Legrominosae \\
\hline Joá & - Solanron sp. - Solanaceae \\
\hline Malva & - Malva parviflora L. - Màlvaceae \\
\hline Mandacaru & - Cereus sp. - Cactaceae \\
\hline Milho & - Zea mays L. - Gromineae \\
\hline Picão preto & - Bidens pilosa L. - Compositae \\
\hline Pimenta do reino & - Piper nigmon L. - Piperaceae \\
\hline Soja & - Glycines max (L) Merril - Legrominosae \\
\hline Soja perene & - Glycine wightii Willd. - Leguminosae \\
\hline Tiririca & - Cyperus rotundus L. - Cyperaceae \\
\hline
\end{tabular}

Além disso, obtivemos exemplares de solo de mata, solo de cerrado e de algumas gramíneas não identificadas.

As amostras de solo foram processadas combinando-se os métodos de peneiramento com Baermann modificado, procedi mento já descrito por MONTEIRO (1970). As peneiras usadas foram as de nümeros 20,100 e 200 do sistema U.S.S.S.S., mar- 
ca Granutest.

No caso das raízes, as amostras foram cortadas em pequenos pedaços de aproximadamente l centfmetro, com auxílio de tesoura e, em seguida, fragmentadas em liquidificador com água cobrindo as facas, durante cerca de trinta segundos. Final mente, fazia-se passar a suspensão obtida pela peneira nümero 20 a fim de se eliminar as impurezas maiores e facilitar a observação dos nematóides.

A fixação dos exemplares foi feita empregando-se a so lução referida como T.A.F. forte, descrita por MONTEIRo (1970). A desidratação foi realizada segundo o "método da desidratação vagarosa", descrito por LoRDELlo (1965). Todavia, em muitos casos, os espécimens imersos em glicerina $5 \%$ foram mantidos em estufas a $40^{\circ} \mathrm{C}$ e não à temperatura ambiente.Para tanto, o recipiente tipo "Siracusa" em que estavam os nematóides era recoberto quase totalmente por uma placa de vidro, a fim de se evitar uma desidratação demasiadamente rápida e possíveis danos nos exemplares. Com essa modificação no méto do póde-se obter boas montagens permanentes em um espaço de tempo bem menor.

Foram preparadas làminas temporárias e principalmente permanentes.

No primeiro caso, os nematóides foram transferidos da ägua para lâminas com pequeno volume de solução de formol 6\%: para a Iutagem empregou-se uma mistura de parafina e vazelina branca na proporção de $2: 1$, conforme recomendação de LORDELLO 
$(1953)$.

As láminas permanentes foram montadas em glicerina, $\underline{-}$ tilizando-se na lutagem o ingrediente conhecido como "Zut", in troduzido por THaRNE (1935) e de uso corrente em laboratórios de Nematologia.

$\mathrm{Na}$ montagem das lâminas colocou-se pedaços de fibra de vidro sob as lamínulas, como calços, com o intuito de evi tar alterações na forma dos nematóides.

Para a preparação das ilustrações recorreu-se a câmara clara, adaptada a um microscópio monocular.

Na mensuração dos exemplares, os seguintes valores fó ram considerados:
$a=\frac{\text { comprimento do corpo }}{\text { largura do corpo }}$
$b=\frac{\text { comprimento do corpo }}{\text { comprimento do esôfago }}$
$c=-\frac{\text { comprimento do corpo }}{\text { comprimento da cauda }}$
$V=\frac{\text { distância da região labial a vulva }}{\text { comprimento do corpo }} \times 100$
$L=$ comprimento do corpo 


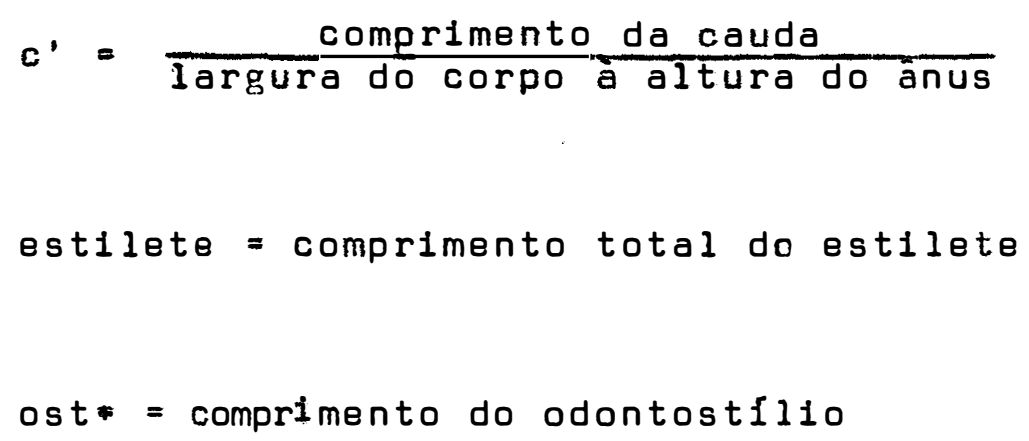
mais foram introduzidos por diferentes autores. 
4 - SÓMULA HISTORICA E SITUAÇÃO ATUAL DE LONGIDORIDAE

THORNE (1935) estabeleceu Longidorinae como subfamilia de Dorylaimidae de Man, 1876 (sensu Thorne, 1935) para compreender os gêneros Longidorus (Micoletzky, 1922) Thorne 1934 e Xiphinema Cobb, 1913.

Em 1939, na sua notável monografia sobre os nematóides da superfamília Dorylaimoidea, THORNE adicionou o gênero novo Longidorella à subfamília.

Loos (1949, 1950) acrescentou o gênero novo Xiphinemella Loos, 1950 (= Taprobanus Loos, 1949, nome pré-ocupado). CHITWOOD (1957) conduziu Longidorinae à sinonimia de Tylencholaiminae Filipjev, 1934 mas, tal proposição, conforme relatou LORDELLO (1965), não foi aceita pela maioria dos auto res.

MEYL (1961) elevou Longidorinae à condição de famí - 
lia, compreendendo apenas os gêneros originais.

SIDDIQI, HOOPER e KHAN (1963)adicionaram o gênero novo Paralongidorus à familia.

DALMASSO (1969) propós a subfamilia nova Xiphinemat nae como subdivisäo de Longidoridae para conter o gènero Xiphinema, enquanto Longidorinae compreenderia Longidorus e Pa ralongidorus.

COHN e SHER (1972) propuseram a subdivisão de Xiphi-nema em oito subgèneros (Xiphinema, Radiphinema, Krugiphinema. Elongiphinema, Halliphinema, Basiphrnema, Rotundiphinema 8 Diversiphinema).

KHAN a AHMAD (1975) propuseram a elevação de Longidọ ridae à categoria de superfamilia, passando as subfamilias à condição de familias.

MONTEIRO (1976) descreveu o gênero novo Kiphidorus colocando-o na familia Longidoridae sensu Meyl, 1961. A pro posição de Xiphidorus veio complicar a subdivisão de Longidori dae, isto é, exigiria emendas nas diagnoses caso fossem aceitas as divisöes da familia propostas por DALMASSD (1969). Preferimos não fazè-lo. por ora.

Do exposto e acompanhando no que couber as conclusöes de LORDELLO (1965) e MONTEIRO (1970, 1975) em suas teses, adotamos a seguinte situação sistemätica para Longidoridae:

Filo Nemata (Rudolpbi, 1808) Cobb, 1919

Classe Adenophorea (von Linstow, 1905) Chitwood, 1958

Ordem Dorylaimida Pearse, 1942 


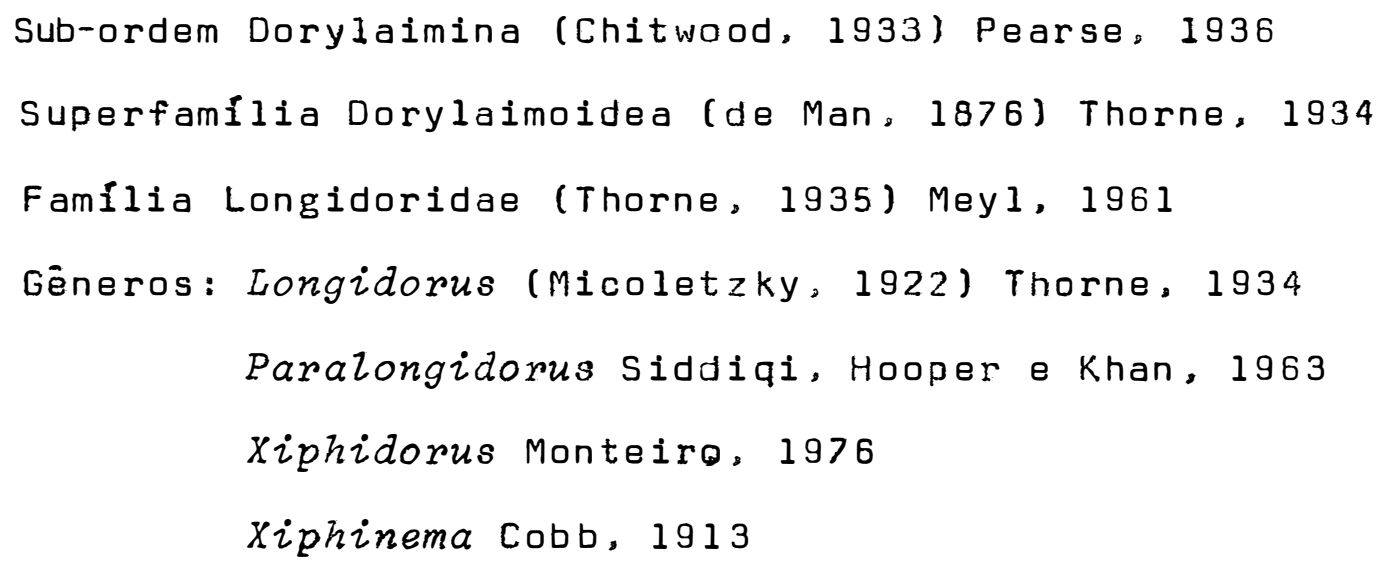


5 - HISTÓRICO DA FAMTLIA LONGIDORIDAE NO BRASIL

As pesquisas referentes a Xiphinema, em nosso Pais, iniciaram-se com os trabalhos de LORDELLO, em 1951. Nesse a no, o citado autor descreveu as espécies $X$. brasiliense (LORDELLO, 1951 a) e $X$. campinense (LORDELLO, 1951 b).

LORDELLO (1955) descreveu $X$. krugi e apresentou uma chave para a classificação das 29 espécies até então conhecidas.

LORDELLO e COSTA (1961) descreveram X. brevicolle, a partir de material coletado na rizosfera de cafeeiros.

CARVALHO (1962 b) descreveu $X$. itanhaense com base em exemplares obtidos na rizosfera de bananeiras.

CARVALHO (1965) descreveu $X_{0}$ paulistanum a partir de material coletado na rizosfera de plantas ornamentais. SHARMA e SHER (1973 c, 1974) relataram a ocorrència 
de uma espécie não identificada de Lonaidorus associada a ca caueiros, no Estado da Bahia.

MONTEIRO (1976) descreveu o gênero novo Xiphidorus

(espécie tipo $X$. yepesara) a partir de material coletado na rizosfera de maracujazeiros do Estado de Pernambuco.

Näo existe nenhuma referência a ocorrència do gênero Paralongidorus em nosso meio.

Apresentamos, a seguir, uma relação das espécies de Longidoridae assinaladas no Brasil, com as respectivas indica ções dos locais de origem dos materiais e das plantas hospe deiras associadas.

Xiphinema americanum Cobb, 1913: ornamentais, São Paulo (CARVALHo, 1955); bananeira, São Paulo (CARVALHo, 1962 a): cacaueiro, Espírito Santo (SHARMA e SHER, 1974). Xiphinema basiri siddiqi, 1959: amoreira e pimenteira, Bahia (SHARMA e LOOF, 1972): seringueira, Bahia (SHARMA e LOOF, 1973 a): gladiolos, Bahia (SHARMA \& LOOF, 1975 a).

Xiphinema brasiziense Lordel1o, 1951: batata, São Paulo (LOROELLo, 1951 a): bananeira, São Paulo (CARVALho, 1962 b): vegetação de cerrado, Goiás (HUANG e CUPERTINO, 1976). Xiphinema brevicolle Lordello \& Costa, 1961: cafeeiro, São Paulo (LORDEllo e COSTA, 1961): cafeeiro, São Paulo (MONTEIRO, 1970); cacaueiro, Bahia (SHARMA \& LOOF, 1974 a). Xiphinema elongatum Sch.Stek. \& Teun., 1938: arroz, guandu, repolho e soja, São Paulo (LoRDELLo, 1951 b) g guandu São Paulo (LORDEllo e ARRudA, 1956): bananeira, São Paulo 
(CARVALHO, 196:2a).

Xiphinema ensiculiferum (Cobb. 1893) Thorne, 1937: bananeira, Bahia (SHARMA e SHER, 1973a); cacaueiro, Bahia ( SHARMA E SHER, 1973c).

Xiphinema krugi Lordello, 1955: ess. florestais, são Paulo (LOROELlo, 1955): pessegueiro, São Paulo (LOROELLo e Za MITH, 1960); cafeeiro, São Paulo (MONTEIRO, 1970); seringuei ra, Bahia (SHARMA e LOOF, 1973a) ; cafeeiro, Paraná (LOROELLO et $a$ ii , 1974).

Xiphinema setariae Luc, 1958: amoreira, abacaxizei ro, pimenteira e portulaca-de-jardim, Bahia (SHARMA e LOOF, 1972); seringueira, Bahia (SHARMA e LODF, 1973a) ; goiabeira, Bahia (SHARMA e LOOF, 1973b); bananeira, Bahia (SHARMA e SHER, 1973a); citrus, Bahia (SHARMA e SHER, 1973 b): cacaueiro, Bahia (SHARMA e SHER, 1973c, 1974): cacaueiro, Bahia (SHARMA e LOOF, 1974a); pimenteira do reino e cravo da India (SHARMA e LOOF, 1974b)。

Xiphinema spp. : cacaueiro e seringueira, Bahia (SHARMA, 1972); abacaxizeiro, pimenteira e maracujazeiro, Bahia (SHARMA e LOOF, 1972); cacaueiro, Bahia (SHARMA e SHER, 1973c): goiabeira, Bahia (SHARMA e LOOF, 1973b): cana-de-açúcar, São Paulo (NOVARETTI et alii, 1974); cafeeiro, Paraná (LOROELLO et alii, 1974) ; gladíolos, Bahia (SHARMA e LOOF, 1974a): cacaueiro, Espírito Santo (SHARMA e SHER, 1974): cajueiro. Ceará (LIMA et alii, 1975); vegetação de cerrado, Goiás (HUANG et alii, 1976); abacaxizeiro, feijoeiro, mamoeiro e 
Pinus sp., Espirito Santo (SHARMA, 1976).

Longidorus ssp.: cacaue1ro, Bahia (SHARMA a SHER

1973c), cacaue1ro, Espír1to Santo (SHARMA a SHER, 1974 ). Xiphidorus yepesara Monteiro, 1976: maracujazeiro, Pernambuco (MONTEIRO, 1976). 


\section{6 - SOMULA MORFOLOGICA DA FAMILIA LONGIDORIDAE}

$$
\text { Comprimento e forma do corpo: em Longidoridae, o }
$$

corpo é cllindróide, fino e alongado, afilando-se nas extremi dades; o afilamento, na parte posterior, pode ser abrupto ou gradativo, o que determina o aparecimento de diferentes t1 pos de cauda. Esta família compreende os maiores nematóides parasitos de plantas conhecidos, podendo o comprimento total variar de 1,5 a $10,0 \mathrm{~mm}$ ou mais. As larvas assemelham-se muito aos adultos no aspecto geral, ocorrendo variações acen tuadas na forma de cauda, em diversas espécies. Quando mortos pelo aquecimento gradual, os espécimens assumem a forma a proximada de um $C$.

Região Labial: é geralmente lisa e arrendodada, contínua ao corpo ou dele separada por uma pequena depressão: os lábios são fundidos. As papilas labiais são diminutas, nem sempre visíveis com clareza.

Cauda: as características da região caudal, particularmente no gènero Xiphinema, são bastante variáveis e apre- 
sontom grande importância nos estudos sistemáticos. Com relação a forma da cauda, os seguintes tipos podem ser definidos:

Hemisferóide: cauda uniformemente arredondada, também roforida como obtusa. Ocorre em Xiphinema ensiculiferum, Xi phinema surinamense e divorsas outras espéclos.

Conólde: cauda de formato cônico, de comprimento muito variável, com a extromidado podendo ser lovemente arradondado. Encontroda em Xiphinema elongatum, Xiphidorus yepesara, além de várlas outras espécles de Longidorus, Paralongidorus e Xiphinema.

Subconó1do: cauda de formato basicamente cônico, porém, com a extramidade marcadamento arredondada. Encontrada em Xiphinema krugi a várlas espócles de Longidorus e Paralongido rus.

Digitada: cauda que termina om um opēndice digitiforme de comprimento variāvol (tambóm roferido como mucro ou mami10), o qual pode s1tuar-se em posição central, como em Xiphinema brasiliense, au aprosontar-se voltado ventralmente, como om Xiphinema setariae certos populoçōes do Xiphinema kru$g i$

Filiforme: cauda uniformomente afilada, geralmente muito longa. Encontrada em Xiphinema filicauáatum Loof \& Maos, 1972, Xiphinema Zongicaudatum Luc, 1961 o outras aspöc1es do Xiphinema.

Aporolho digestivo: constituido pelo esofago o intostino. 
Esôfago: o estilete é longo (90-290 mlcros) e composto de duas partes distintas: o odontostilio e o odontóforo ou porção basal. Embora de naturezas diferentes, estas duas es truturas atuam como uma única entidade funcional. Em Xiphinema e Xiphidorus estäo presentes bulbos bem desenvolvidos à base do odontóforo, enquanto que em Longidorus e Paralongidorus =os mesmos são multo reduzidos ou estão ausentes. C1rcundando o odontostilio encontra-se o anel-gula. Em Longidorus * Paralongidorus este órgäo é slmples a situa-se bem anterior mente, próximo à extremidade anterior do nemató1de. No caso de Xiphinema e Xiphidorus - há do1s ané1s bastante próximos, sendo o posterior mals evidente; ambos localizam-se pouco aclma da junção odontostilio - odontóforo. Em seguida existe um tubo fino e longo, às vezes retorcido, o qual termina om uma estrutura mais larga e expandida, referida por DALMASSO (1969) como "bulbe musculo-glandulalre". Nestéórgão podem ser observadas as glándulas esofaglanas, uma dorsal e duas subventra1s, cujas caracteristicas säo importantes na separaÇão dos gêneros. Assim, sogundo LOOF a coomans (1972), Xiphinema caracteriza-se por apresentar o núcloo da glàndula dorsal arrodondado e bem malor que os núcloos das glándulas subventra1s. Em Longidorus o Paralongidorus a núcloo da glândula dorsal é alongado a monor que os das glándulas subvontra1s. Alóm disso, a distâncla ontre os núcloos das glândulas dorsal e subvontrals ó consideravelmonto maior em Xiphinema que naquolos göneros. Xiphidorus aprosenta as 
glàndulas com as mesmas caracteristicas de Longidorus o ParaZongidorus (MONTEIRO, 1976). As larvas podem apresontar odontostilios de substitulção, que tomam o lugar dos funcionals quando ocorrem as, ecdises. Nos adultos pode-se obsorvar tambóm, às vezos, uma ostrutura do forma geralmento triangular, reforida por DALMASSO (1969) como "vestigium", o quo reprosonta um odontostilio rudimentar.

Intostino: Apresenta-se soparado do esôfago polo cárdia, uma válvula quo podo sor cánlca ou larga e achatado, con formo as aspécies consideradas; om multos casos, a cärdia mos tra-sc bastante obscura dificultando a suo observação o ostudo. O Intastino oprasenta-so como uma astrutura cilindröido longa, om cujo porte posterior diforonciom-se o pró-roto e o reto: o pré-reto nem sempro podo sor caracterizado com clareza, oo passo quo o roto ó bom avidente, sendo ropresontado pe la rogiäo bastante estre1to obsorvado oo final do intestino. As cólulas intostinals paracom ostar cholos do granulaçós eg curacidos. 0 ànus situa-so um uma depressão pouco acontuada. Orgãos Sensorials

Anfldios: os anfidios tambóm constituom importonto cara tor difaroncial ontro os gônoros de Long1doridae. Em. ParaIongidorus e Xiphinema os aborturas anf1d1a1s säo roprosontados por fendas largas a a ampula tom, geralmento, a forma do um estribo invortido ou do um funil (SIDOIQI, 1965 ; HOOPER e SOUTHEY, 1973); por outro lado, do acordo com MONTEIRO (1976), Xiphidorus e Longidorus oprosentom os aborturos 
como fondas diminutas o vostibulo na forma de duas bolsas ou lobos unidos. E preciso dostacar poróm, que aste critério não é absoluto o sim auxiliar, uma vaz que variações podom ocorror nas caracteristicos dos anfldios om Xiphinema (WRIGHT, 1965), Eongidorus a Paralongidorus (HEYNS, 1966a,b; ABOUL-EID, 1970).

Hemizonidio: aporoco ventralmente à altura do esófago. sob a cuticula, ne forma do um minúsculo ponto refringento (DALMASSO, 1969). Outros autoros considoram quo o homizonidio assomolha-se mals a umo comissura.

Homizónio: monor quo o homizonidio o tambóm situodo ventrolmento no esófago.

\section{Sistama Norvoso}

Anel Nervoso: Como nos domals grupos des nomatóldos, ¿ oncontrado c1rcundando o csôfogo. GOODEY \& HOOPER (1963) afirmaram quo o anol norvoso cm Longidoridao ó duplo, astando o primoiro associado ao homizonidio o o segundo ao hemizînio. Dc acordo com DALMASSO (1969), o sogundo onol só é visivol em exomplaros vivos ou muito bom fixados.

Sistama oxcretor: ó pouco conhecido. Sabo-se de prosonça do olovado númoro do células associodas a poros, oo lon go das cordas longitudina1s. Sogundo DALMASSo (1969), astas ostruturos constituom os únicos órgãos conhecidos quo devom Intorvir no oxcroçäo dos Longidoridao.

Aporoliho repredutor feminino: as fómoas são normalmonto anfidolfas mas, om Xiphinema, oxistom também espácies monodol 
fas (opistodelfas) e pseudomonodelfas. De acordo com COHN e SHER (1972), pode-se diferenciar três tipos de ramo anterior do aparelho reprodutor das fêmeas de Xiphinema a saber: ütero, oviduto e ovário totalmente ausentes - fêmeas monodelfas verdadeiras (opistodelfas); útero e possivelmente oviduto (ou partes dos mesmosl presentes mas, ovário ausente - fêmeas psẹ domonodelfas; útero, oviduto e ovário presentes, ainda que de tamanho menor que o ramo posterior - fèmeas anfidelfas. 0 ra mo posterior é sempre normal, completo. Os ovários são reflexos e revestidos por uma fina membrana; os oogônios dispõem-se em várias filas, ao passo que os oócitos arranjam-se em filas simples. Segue-se o oviduto, um conduto estreito que se liga ao útero através de um esfincter. A forma e o ta manho do útero variam conforme as espécies consideradas e a presença ou não de ovos no seu interior. Pode-se observar ainda, no útero de algumas espécies de Xiphinema, uma estrutura descrita por lUC (1958) como "um órgão globøso e muito mus culoso, que lembra o bulbo mediano do esôfago dos Criconematidae" o órgão Z. Na parede interna deste órgão aparece um número variável de elementos esclerosados, semelhantes a apófises. Embora não se conheça a real função do órgão $Z$, a sua importància em estudos taxonômicos já foi ressaltada por cod MANS (1965) e COHN e SHER (1972). Na região onde ocorre a convergência dos úteros das fêmeas pseudomonodelfas e anfidelfas existe uma estrutura chamada ovijetor; este foi defini do por COHN e SHER (1972) como uma "bolsa dilatada com um 
lümen largo, que se estende dorsalmente no interior do corpo e é delimitado por espessa parede". Nas fèmeas monodelfas e ovijetor também está presente mas, devido a ausência do ramo anterior, apresenta menor tamanho. A vagina pode estender-se até a metada da largura do corpo, em muitos casos. A vulva é representada por uma fenda transversal cujos movimentos de abertura e fechamento são comandados por poderosa mus culatura.

Aparelho reprodutor masculino: os machos de Longidoridae possuem o aparelho reprodutor sem características especiais. Constitui-se basicamente, de dois testículos distendidos que convergem no canal deferente, seguindo-se o canal ejaculador e a cloaca. Os espículos são bem evidentes. Gubernäculo presente. O número de suplementos è geralmente maior em Longidorus -e Paralongidorus que em Xiphidorus e Xiphinema. Segundo DALMASSO (1969), os espermatozóides não possuem flagelo e apresentam o aspecto de diminutas estruturas arredondadas bastante refringentes. Vale destacar que, em diversas espécies, os machos são multo raros ou desconhec1 dos. 
7 - IMPORTÂNCIA AGRICOLA DOS NEMATOIDES DA FAMILIA LONGIDORIDAE

COBB (1913) ao estabelecer o gēnero Xiphinema, afirmou que o mesmo deveria conter um elevado número de espécies, ocorrendo praticamente em todos os continentes. Ressaltou ainda, com base na espécie-tipo $X$. americanum, que tais nematóides deveriam apresentar intenso polifagismo, associando-se às rafizes de inúmeras plantas cultivadas.

Durante a década 1930-1940. THORNE imprimiu novo impulso aos estudos sistemáticos de Dorylaimoldea, havendo estabelecido em 1934 o gênero Longidorus, o qual passou a constituir juntamente com Xiphinema, a entäo subfamília Longidori noe.

Fol todavia, por volta de 1950, que os estudos relativos aos dois gèneros intensificaram-se de maneira notável. Assim, as descriçōes de novas espécies tornaram-se frequentes 
e as demonstrações experimentale da patogenicidade desses nematóides às plantas começaram a ser realizadas.

White (1955), citado por JENKINS a TAYLOR (1967), Pa rece ter sido a autor da primeira demonstraça de patogenicidade das espécies de Xiphinema, havendo relatado os danos pro vocados por $X$. americanum em Pinus sF.. nos Estados Unidos.

SCHINDLER ( 1957 ) verificou, em condições controladas, que $X$. diversicaudatum (M1coletzky, 1927) Thorne, 1939 pro vocara a formação de galhas e engrossamentos generalizados nas raizes de amendoinzeiro, figueira e soja, apresentado as plantas atacadas um crescimento reduzido; em roseiras, o danos foram ainda mals sérios, considerando o autor que infesta ções desta espécie poderiam constituir fator limitante à produção de rosas, em casas-de-vegetação.

PERRY (1958) descreveu os danos provocados ao morangueiro por $X$. americanum e X. chambersi Thorne, 1939, não hạ vendo observado a formação de galhas ou arieas hipertrofiadas nitidas.

GRIFFIN e EPSTEIN (1964) relataram que plântulas de Picea pungens e Picea glauca densata Infestadas artificialmente em viveiros com $X$. americanum, apresentaram crescimento bastante deficlente quando comparadas com as não Infestadas. KIRKPATRICK et alii (1965) observaram a formaçäo de engrossamentos anormals na ponta das rafzes de videiras infestadas artificialmente com $X$. index Thorne \& Allen, 1950; determinaram, na ocasião, que as plantas atacadas apresenta- 
ram, em relação as näo infestadas, reduções de $38 \%$ no peso to tal de rafzes, 89\% no tamanho dos frutos e $60 \%$ no número de Inflorescências.

NORTON (1967) af1rmou que $X$. americanum causara evidente redução no crescimento de Trifolium pratense, em condições de campo e casa-de-vegetaçäo.

COHN (1970) realizou observaçōes in vitro sobre mecanismo de alimentação e danos causados por $X$. brevicolle e X. index em rafzes de laranja azeda, roseira e videira. Verificou que ambas as espécies raramente penetravam nas extremidades das rafzes e que o perfodo de alimentação,num único local, podia variar desde algumas horas até 3 dias. Os sintomas gerais provocados foram escurecimento generalizado das ráizes e colapso em certas áreas do córtex, concordantes com PERRY (1958). Não ocorreu a formação de galhas evidentes como aquelas assinaladas por SCHINDLER (1957).

COHN a ORION (1970) relataram os efeitos da inoculacäo de diferentes niveis populacionais de $X$. brevicolze e $X$. index em laranja azeda, roseira e videira, verificando que a variedade ciftica era a mais sensivel das três plantas hospedeiras.

MILNE et alii (1971) encontraram expressivas populações de $X$. brevicolze associadas a plantas bastante depauperadas de Litchi sinensis, em pomares africanos. Os sintomas gerais eram clorose foliar intensa, florescimento reduzido, queda excessiva de frutos e rafzes com engrossamentos tipicos. 
MCELROY (1972) elaborou uma lista de plantas hospedelras de $X$. bakeri Williams, 1961 no Canadá, Indicando Inclusive o grau de suscetibilidade das mesmas ao parasito. Rosáceas e solanäceas foram as mais danificadas, ao passo que as populações de nematóides diminuiram consideravelmente quan do inoculadas em algumas crucfferas, cucurbitáceas e plantas daninhas. Os sintomas observados, principalmente em rafzes de frambroeseira, morangueipo e tomatelro, variaram desde pequenas áreas necróticas á gajhas bem evidentes.

RUEHLE (1972) relatou a ocorrència de evidente redução no crescimento e vigor de plântulas de Luiquidambar $\boldsymbol{s}$ tyraciflua infestadas por $X$. chambersi, nos Estados Unidos; as rá́zes exiblam áreas necróticas e engrossamentos generalizados.

No Brasil, também já existem vários registros de nematofdes dos g.êneros Xiphinema, Xiphidorus e Longidorus associa dos a Inúmeras plantas cultivadas em evidente depauperamento. Inúmeros outros trabalhos referentes a associação de nematóides da familia Longidoridae a plantas com crescimento deficiente, seja em condições de campo ou casa-de-vegetação, podem ser encontrados na literatura nematológica.

A Importância agrícola deste grupo de nematóides é alnda ressaltada pelo fato de poderem atuar como transmissores de virus.

As pesquisas relacionadas com a transmissão de vírus altamente noolvos às plantas cultivadas por nematóldes inten- 
sificaram-se por volta de 1955, culminando com a primeira com provação experimental do fenômeno em 1958, quando HEWITT, RAS KI e GOHEEN verificaram que $X$. index atuava como eficiente ve tor do "fanleaf virus" da videira.

Sabe-se atualmente que diversas espécies de Xiphinema e Longidorus podem transmitir viroses às plantas, nada existindo a respeito de Paralongidorus \& Xiphidorus.

Entre as espëcies mais frequentemente referidas como transmissoras de vírus pode-se destacar $X$. americanum, $X$. diversicaudatum, $X$. index, L. elongatus (de Man, 1876) Thorne 8 Swanger, 1936, L. macrosoma Hooper, 1961, L. attenuatus Hooper, 1961 (JENKINS e TAYLOR, 1967), X. brevicolle (FRITZCHE e KEGLER, 1968 ; LISKHOVA e SABOVA, 1973) e „X. italiae Meyl, 1953 (COHN et alii 1970: DALMASSO et alii, 1972). 
29.

8 - RESUltados E DisCUSSÃo

\begin{abstract}
Nove espéc1es de Xiphinema foram 1dentificadas no presente estudo, sendo uma delas nova para a Clência. Uma outra constitul referência nova para o Brasil. São apresentados, em segulda, os dados obtidos da mensuraçào dos exemplares brasileiros e observaçöes sobre a sua morfologia. Foram incluidas trés espécies anteriormente determinadas em nosso pais e não encontradas durante este trabalho, a fim de tornar completas as informações relativas ao gènero. Finalmente, apre sentamos uma chave para auxiliar o reconhecimento das espécies de Xiphinema que ocorrem em nossas condlçöes.
\end{abstract}


Xiphinema conericanum Cobb, 1913)

X. americanum Cobb, 1913. Jour. Wash. Acad. Sc1. 3(16): 432-445. (n.sp.)

Dimensöes (em m1cros): Fèmeas - os resultodos das mensurações são apresentados na Tabela 1 .

Observaçöes: como mostrou TARJAN (1969), Xiphinema americanum pode apresentar acentuadas variações em sua morfologia em função de fatores climáticos como o latitude, temperatura e prec1pitação média anual. Os valores que obtivemos para os exemplares nacionals mostraram-se concordantas, de modo geral, com os apresentados por TARJAN, ralativos a 75 populações oriundas de todas as partes do mundo. Apenas os dados referen tes ao comprimento do estilete dos espéc1mes brasile1ros foram superioris à falxa de valores considerada como a mals represen

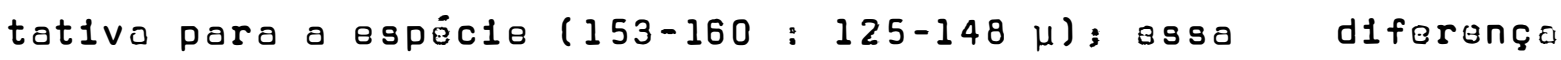
todavia, é absolutamente normal, havendo mesmo populaçōes em que o comprimento do estilete atinge $180 \mu$ ou ma1s. No Bras11. CARVALHO (1955, 1962a) assinalou a ocorráncia de $X$. americanum em duas ocasiöes. Os eximplares coligidos em 1955 , segundo LORDELLO e COSTA (1961), assemelhavam-se muito a $X$. brevicolle, apresentando contudo, o estilete bom mals curto $(108: 156-168 \mu)$. KHAN e AHMAO (1975) consideraram haver suf1clentes evidênclas de que tals espécimes pertencessem a uma nova uspécle e propuseram o nome $X$. saopaoloense para $X$. americanum sensu CARVALHO (1956) non Cobb, 1913. Entretanto, 
- valor que encontramos para o estilete da exemplar que figura no trabalho de CARVALHO fol de $131 \mu$. Como HEYNS (1974a) mos trou que $X$. brevicolle pode apresentar variaçäes em sua morfologia, tendo mesmo obtido espécimens com estilete de comprimen to igual a $136 \mu$, parece-nos que os exemplares de CARVALHO (1955) eram realmente desta espécie. Porém, em vista deste material estar aparentemente perdido, preferimos considerar $X$. americanum sensu CARVALHO (1955) como "nomen dubium". Quanto aos espécimens coletados em 1962, particularmente pelas características da cauda, parece-nos não haver düvida de que se tra tava em verdade da espécie $X$. brevicolle. Sobre o assunto, HEYNS (1974a) opinou categoricamente: "as descriçöes de CARVA LHO (1955, 1962, Brasil) de X. americanum referiam-se indubita velmente a X. brevicolle...". A exemplo de outros países, também no Brasil $X$. americanum encontra-se muito disseminado, sendo este o primeiro registro da espécie no Estado da Paraiba. o fato reveste-se de especial importância por ser o parasito em questão extremamente polífago e comprovado agente transmis sor de viroses. 


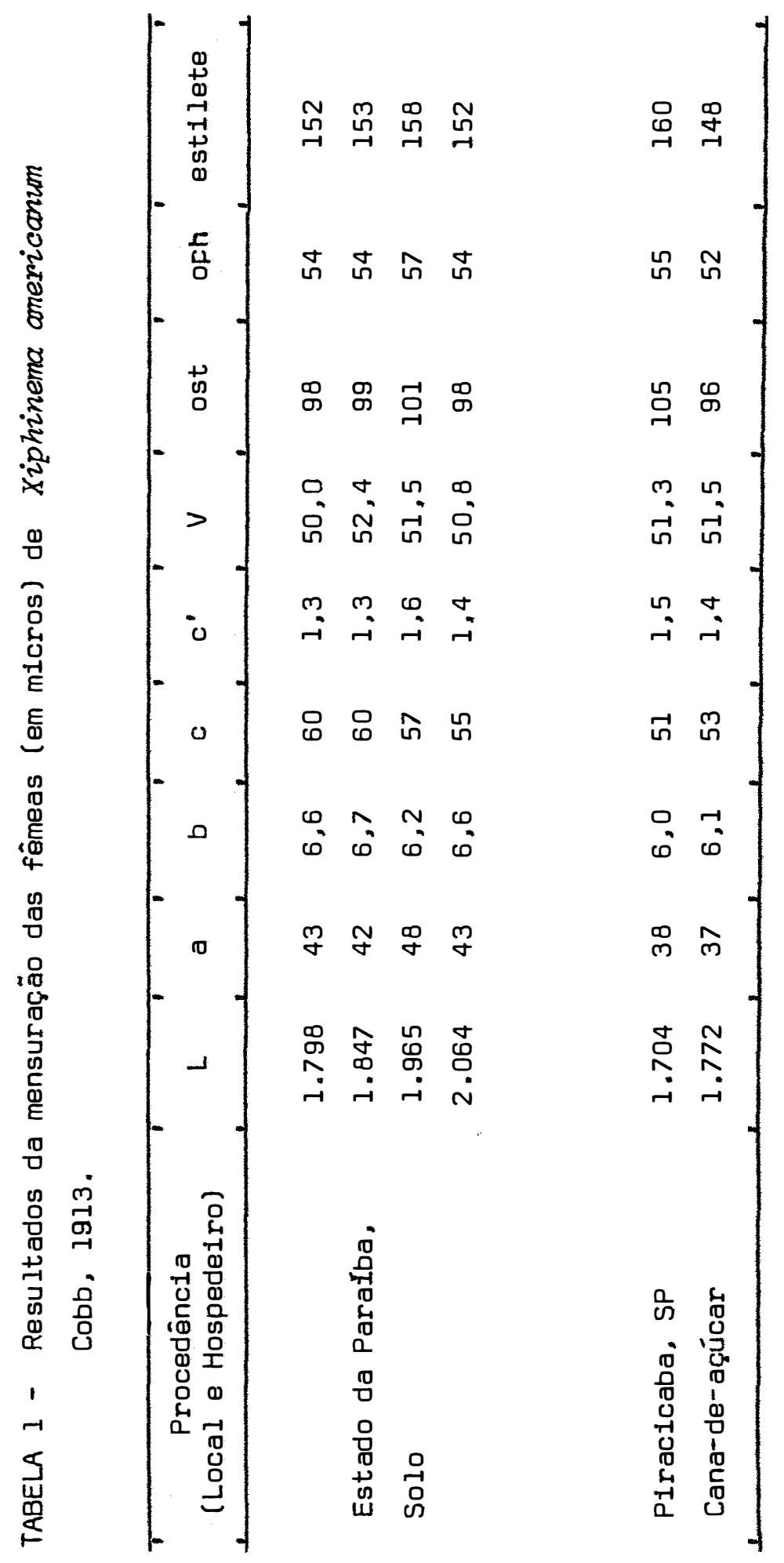


Xiphinema attorodorum Luc, 1961

X. attorodorum Luc, 1961. Nematolog1ca 6: 107-122 (n.sp.)

Dimensões (em micros). Fômeas: os resultados da mensuraçäo dos oxemplares ostão apresentados no Tabela 2.

obsorvaçõos: os dados que obtivemos para os exemplares estudados não se mostraram totalmente concordantes com os da populaçäo-tipo, descrita por LUC na Africa ocidental, sendo as varia ções observadas referentes aos valores "L" (comprimento do corpo) e "b" (comprimento do corpo/comprimento do esófago). Todavia, sabe-se que o valor "b" tem importancia restrita na taxonomia do gênero Xiphinema fHOOPER a SOUTHEY, 1973); quanto ao comprimento do corpo ("L"), verificamos que os exemplares nacionals eram realmente malores que os da descriçäo original $(3,27-3,89: 2,49-2,81 \mathrm{~mm})$, preferindo contudo, considerar mos tals diferenças como decorrentes de variaçöes ecológicas. Aliás, essa possibilidade já fora reconhecida por LUC na diag nose da espécle, afirmando haver encontrado uma populaçäo na risofera de cafeeiros, na própria Africa, em que o comprimento médio do corpo era de $2,91 \mathrm{~mm}$. As caracteristicas do estflete, da cauda e da vulva, de grande interesse sistemático no gênero em estudo, concordaram de maneira marcante. Não conseguimos encontrar machos de $X$. attorodorum para complementar as observações relativas a espécia. Este constitui o primei- 
ro registro de $-X$. attorodorum om nosso Pais.

\section{Xiphinema brasiliense Lordello, 1951}

X. brasiliense Lordello, 1951. Bragant1a. 11:87-90 (n.sp.)

Oimensöes (em micros). Fêmeas: aos dados relativos à mensuração são apresentados na Tabola 3.

Observações: LORDELlo ao descrever esta espécle baseou-se em um ünico oxomplar do fômea e apresentou um valor c quo não cor rospondla às llustraçöos contidas no trabalho, oquívoco aponta do por STURHAN (1963). Os dodos ora obtidos da mensuraçäo do seis fómoas mostraram-so concordantos com os do LORDELLO, ropresontando alnda subsidio ao conhecimento das variações que a espócle podo evidencior, especialmente nos valores $\underline{V}, \underline{c^{\prime}} \quad$ e roforentos ao estilete. CARVALHO (1962b) doscrevou o ospécle X. itanhaense, am material colotado ne rizosfera do bananeiras, considerando-a extremamento somelhante a $X$. brasiliense; na diognose, o autor justificou a nova espéc1o por apresentar, em rolação o X. brasiliense, monor comprimonto do corpo (3,4 ou $1,6: 2,1 \mathrm{~mm})$, vulva situada mals posteriormento $(30,5: 27,9 \%)$ o um mamilo caudal mais curto (valor s' menor). Contudo, os

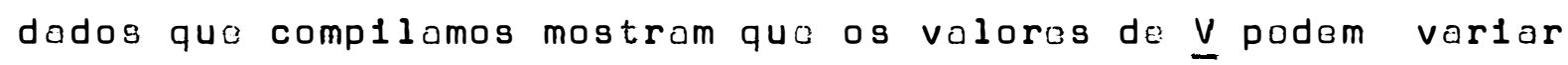
realmonto $(26,8-30,5 \%)$, assim como o comprimento do momilo 
caudal $\left(c^{\prime}=1,0-1,4\right) . \quad \operatorname{COHN}$ e SHER (1972), ao procederem a um estudo comparativo entre exemplares considerados de $X$. bra siliense, provenientes da Guatemala, Nigéria e Ceilão, e três síntipos de $X$. itanhaense, já haviam ressaltado o fato das diferenças observadas serem insignificantes, a propósito, nas populações de $X$. brasiziense oriundas da Guatemala e da Nigéria, os exemplares apresentaram valor médio para o comprimento do corpo em torno de $1,6-1,7 \mathrm{~mm}$. Ademais, calculando-se o comprimento do corpo do espécimen figurado por CARVALHO obtivemos valor de $2,1 \mathrm{~mm}$. O valor V calculado da ilustração é igual a $27,1 \%$. Em vista disso, julgamos ser correta e väli da a proposição de COHN e SHER, considerando $X$. itanhaense co mo sinônimo de $X$. brasiziense.

\section{Xiphinema brevicolle Lordello \& Costa, 1961}
X. brevicolle Lordello \& Costa, 1961, Revo Brasil. Biol. 21: $363-366(n \cdot s p$.

Dimensões (em micros). Fêmeas: os resultados obtí dos da mensuração dos exemplares estão contidos na Tabela 4.

Observações: Os dados obtidos da mensuração dos exemplares co letados na rizosfera de cafeiros concordaram com os valores da descrição original e os apresentados por MONTEIRO (1970). Os espécimens coligidos em cana-de-açücar e vegetação de cer- 
rado mostraram pequenas variaçōes com relação ao material-tipo, exibindo estilete e comprimento do corpo de valores inferiores. Tals diforenças devem ser admitidas como normais, pois, HEYNS (1974b) observou variaçöes bem mals acentuadas entre os caracteres morfológicos de $\not$. brevicolze, em estudo realizado com diversas populações oriundas da Africa do Sul. COHN (1969), em Israel, descreveu o macho da espécie, até então desconhecido; este trabalno parece ter passado despercebido a HEYNS (1974b), que descreveu alguns exemplares de machos, consideran do-os como os primeiros conhecidos. X. brevicolle deve merecer novos estudos, em nosso pais, especialmente relativos as suas plantas hospedeiras e distribulção geográfica, porque constitui-se em espécie comprovadamente transmissora de viroses.

Xiphinema elongatum Schuurmans Stekhoven \& Teunissen, 1938

X. elongatum Sch. Stek. \& Teun., 1938. Inst. Parcs Nat. Congo Belge, Bru xelles 22, 229 p. (n. sp).

Dimensões (em micros). Fêmeas: os dados referentes a mensuração dos exemplares são encontrados na Tabela 5.

Observações: devido ao fato da descrição original de X.elongatum conter dados insuficientes sobre a morfologia e ilugtra- 
ções pouco precisas dos espécimens (COHN e SHER, 1972). TARJAN e LUC (1963) redescreveram a espécie, com base no holótipo. Os dados que compilamos, ao curso deste trabalho, mostraram-se plenamente concordantes com os apresentados por TARJAN 8 LUC. X. pratense Loos, 1949 e $X$. campinense Lordel10, 1951, foram conduzidos a sinanimia de $X$. elongatum (TARJAN \& LUC, 1963), assim como $\not$. truncatum Thorne, 1939 (COHN SHER, 1972), havendo autores que discordam desta última proposição (HEYNS, 1974a). Ao confrontarmos os valores ora obtidos para $X$. elon gatum com os apresentados por LORDELLO, na descrição de $X$. campinense, pareceu-nos realmente impossivel a separação das duas espécies: assim sendo,julgamos välida a proposição de TARJAN \& LUC e consideramos $X$ campinense sinōnima de $X$. elon gatum. Qs machos desta espécie são extremamente raros, havendo três espécimens sido descritos por HEYNS (1974a). Em verdade, ao propor $X$. truncatum como sinonfmia de $X$. eZongatum, COHN e SHER (1972) consideraram que o exemplar macho incluido por THORNE na descrição de $X$. truncatum passava a constituirse então, no único espécimen macho de $X$. elongatum conhecido; todavia. como esta proposição tem sido contestada, preferimos aceitar a citação de HEYNS como mais välida. $\Varangle$. elongatum ë uma espécie bastante cosmopolita, havendo sido assinalada em várias partes do mundo. Observamos que, tal como na Austrália, Hawa11 e Africa do Sul, constitui-se em parasito muito frequen te de gramíneas, particularmente da cana-de-açúcar; aliás, este é o primeiro registro da espécie nesta cultura, em nosso pais. 


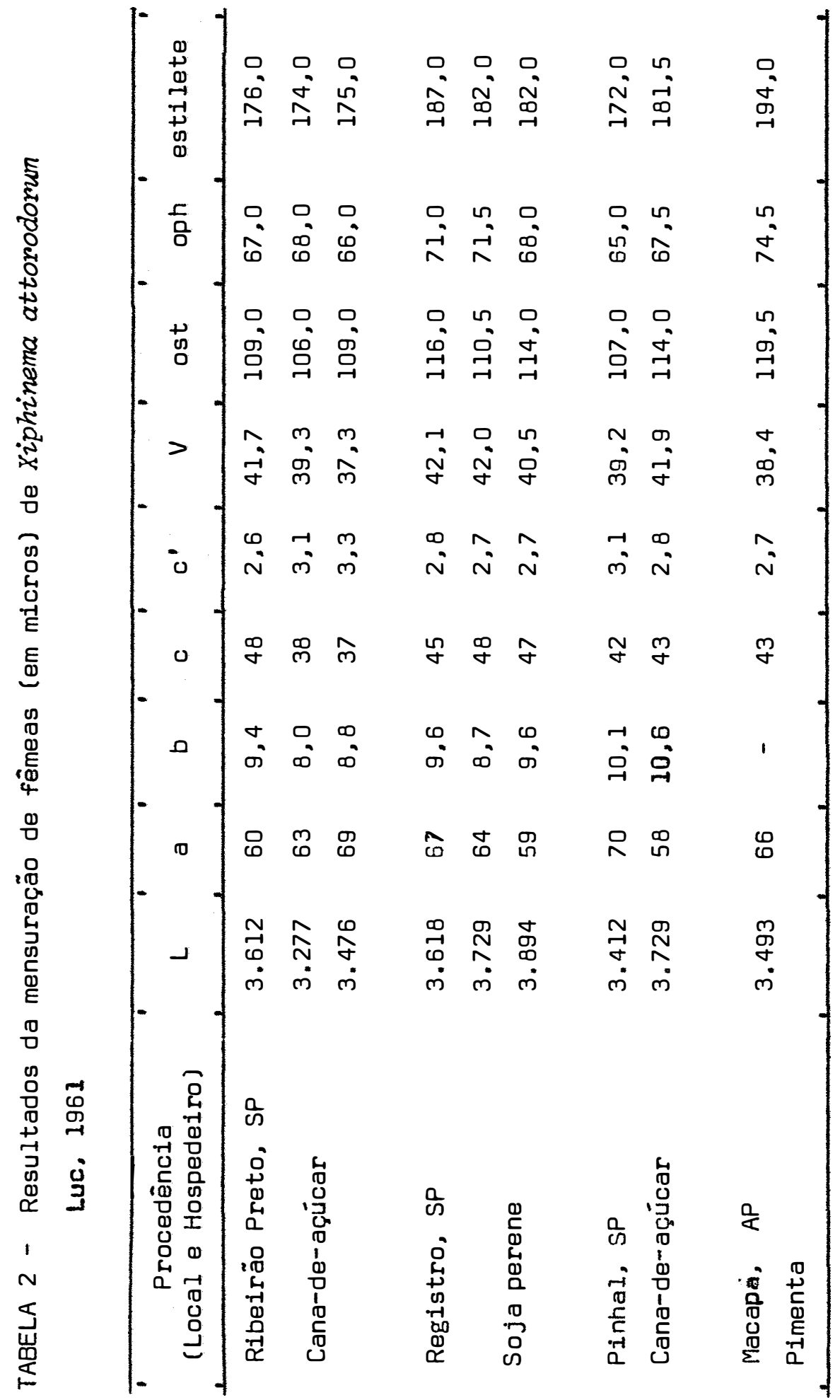




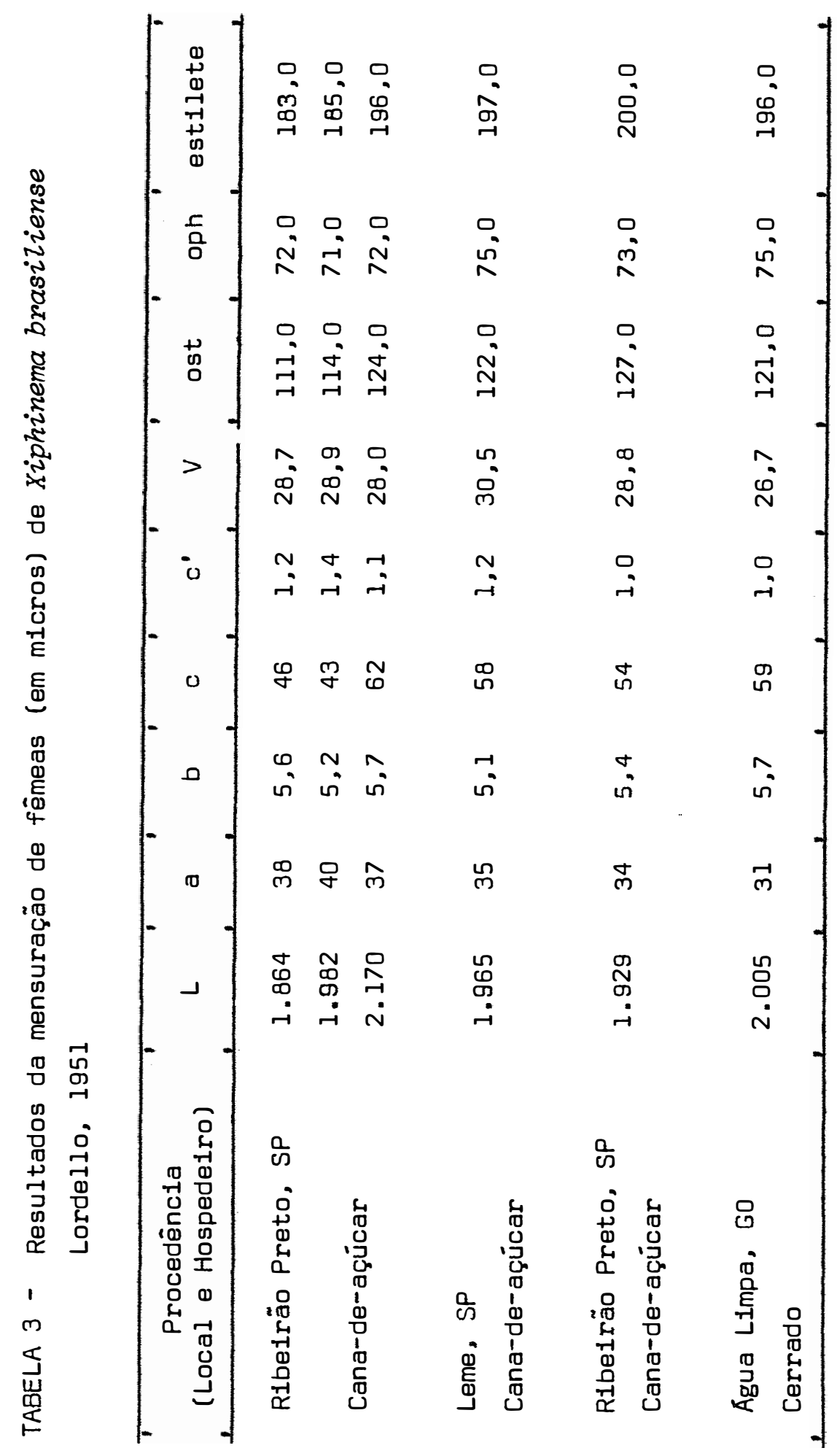


40.

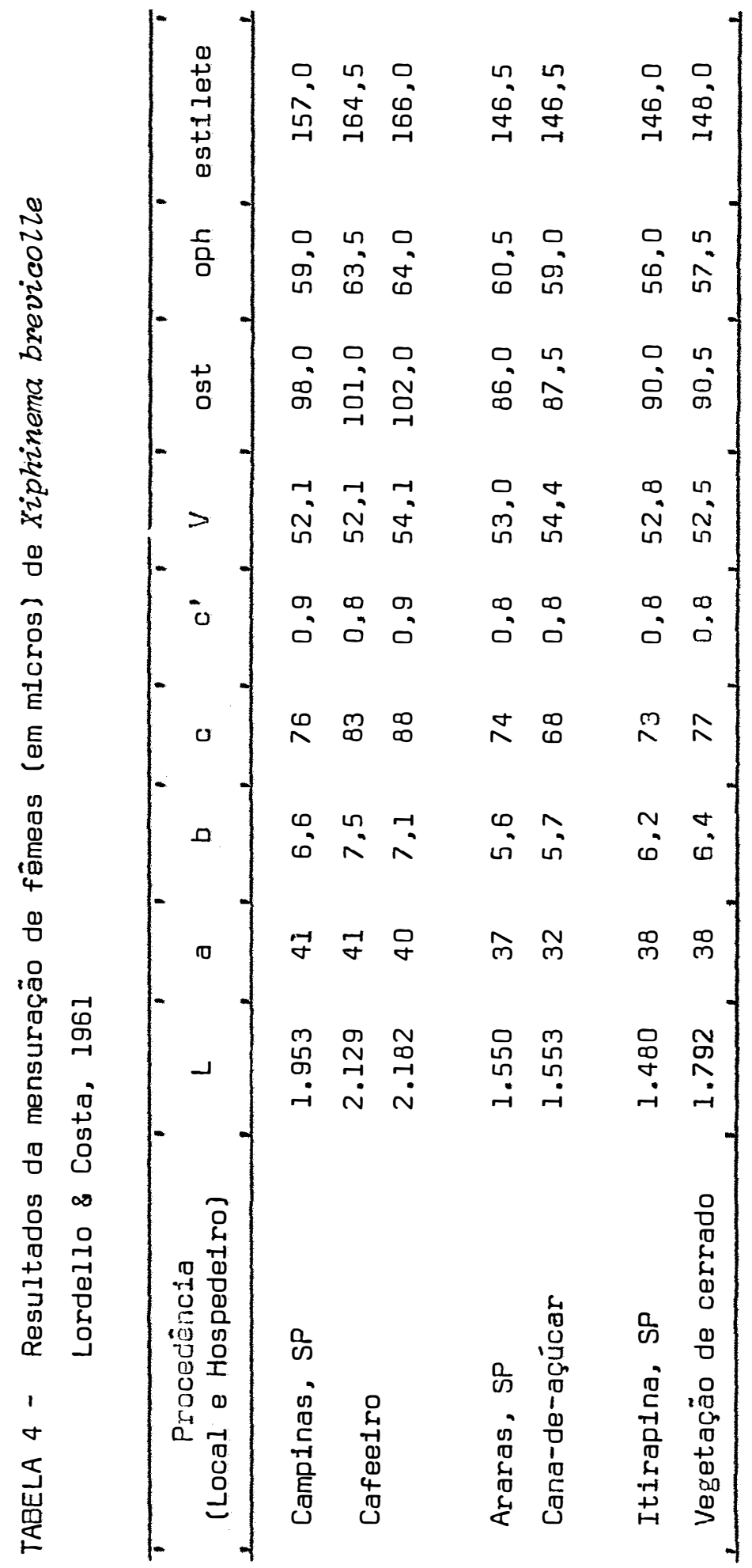




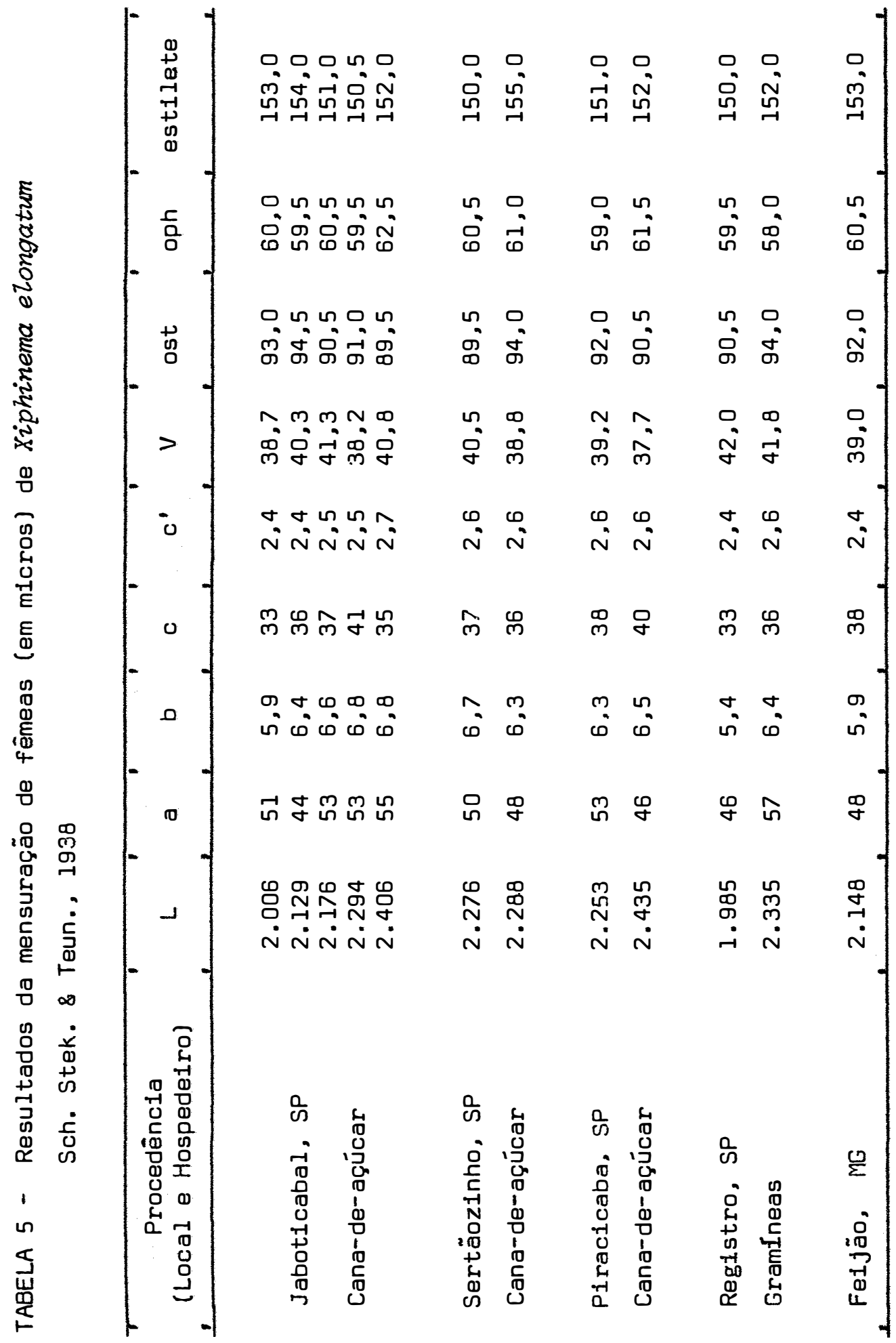




\section{Xiphinema krugi Lordello. 1955}

X. Krugi Lordello, 1955. Proc. Helm. Soc. Wash. 22: 16-21 (n.sp).

Dimensões lem micros]. Fêmeas: os dados relativos a mensuração dos exemplares são apresentados na Tabela 6.

Macho $(n=1): L=2059 ; a=38,0 ; b=6,3 ; c=53$; $c^{\prime}=1,1 ;$ ost $=107 ;$ oph $=66 ;$ estilete $=173$; espiculos $=60$, suplementos $=3$ (além do par ada nal).

Observações: LORDELLO, na descrição original, afirmou que $X$. krugi representava uma forma intermediária entre as espécies verdadeiramente anfidelfas e monodelfas; baseou-se, para tal. no fato das fèmeas estudadas apresentarem o ramo anterior do aparelho reprodutor "muito reduzido e bastante obscuro", constituido apenas pelo ütero e o oviduto, os quais eram separados por uma nitida constriçäo. A cauda, segundo o autor, era cur ta e subconóide. Esta espécie pode evidenciar porém, como ressaltaram MONTEIRO (1970) e FREDERICK a TARJAN (1974), varia ções pronunciadas na forma da cauda; assim, os citados autores relataram a ocorrência de populaçōes em que os exemplares apre sentavam a cauda claramente digitada. Em nosso estudo, onde mais de duzentas fêmeas de $X$. Krugi foram observadas, verificamos que a maior parte das mesmas exibia a cauda digitada, sendo este apêndice digitiforme de tamanho variável e dirigi do para a parte ventral do corpo: vale destacar que os espéci- 
mens com cauda subconoidal, embora em menor nümero, apareceram em amostras oriundas de quase todos os estados incluidos na presente pesquisa. Quanto ao apareino reprodutor das fêmeas, observamos que o ramo anterior apresentava-se bastante atrofiado e, com relativa frequência, reduzido apenas a um saco pré-vulval ou uterino. Somente alguns espécimens provenientes do Estado de Minas Gerais possuiam o ütero anterior bem desenvolvido, praticamente com as mesmas dimensões do posterior. De um modo geral, os dados que encontramos para os exemplares nacionais mostraram-se plenamente concordantes com os de FREDERICK a TARJAN (1974), compilados a partir de quatro diferentes populações obtidas, nos Estados Unidos. 0 confron to com os dados de MONTEIRo (1970) revelou igualmente uma evidente coincidências este autcr apresentou contudo, valores de $\underline{V}$ aparentemente muito altos para a espécie $(37,2$ - 41.0: 33,4 - 34,2\%), considerando tais variações como normais. A este respeito, cumpre destacar o fato de havermos também encontrado espécimens com valores de $\underline{V}$ abaixo da população-tipo $(30,5-31,2: 33,4-34,2 \%)$ confirmando que também em nematóides ocorrem variações, notadamente morfométricas. As espécies X. denoudeni toof \& Maas, 1972 e X. Zoosi Southey \& Luc, 1973, foram colocadas na sinonímia de $\not$. krugi por LAMBERTI a TARJAN (1974). Comparando cuidadosamente os dados e ilustrações contidos nas descrições de $X$. denoudeni e $X$. $Z$.0osi com os valores que obtivemos, pareceu-nos impossível, sem düvida, separä-las de X. krugi; assim sendo, consideramos välida a 
proposição de LAMBERTI e TARJAN, considerando $X$. denoudeni e X. Zoosi como sinōnimos de $X$. krugi. E necessário lembrar todavia, que o trabalho de FREDERICK e TARJAN onde eram discutidas as variações morfológicas de $X$. krugi, só foi publicado de pois da descrição das espécies ora sinonimizadas, o que certamente impediu o estabelecimento de diagnoses mais criteriosas por parte de LOOF e MAAS e de SOUTHEY e LUC. Finalmente, devemos destacar a presença de um exemplar macho em uma das populaçōes de $X$. krugi que estudamos: tal espécimen parece-nos ser. pelos fatos relatados a seguir, o segundo conhecido em todo mundo para a espécie. Loos (1949) descreveu um exemplar macho, em população oriunda do Ceilão, como sendo de X. ensiculí ferum (Cobb, 1893) Thorne, 1937; COHN e SHER (1972) consideraram que os exemplares de LoOS eram, em verdade, de $X$. krugi. SOUTHEY e LUC (1973) redefiniram porém, a espécie $X$. ensicuziferum e propuseram que a população estudada por loos passasse a constituir a nova espécie $X$. Zoosi. Como admitimos anteriormente que $X$. Zoosi é sinônima de $X$. krugi, o macho descrito por Loos representa então o primeiro exemplar conhecido des ta espécie. Confrontando-se os dados obtidos da mensuração do espēcimen brasileiro com os apresentados por souTHEy e LUC (1973) para o macho de Loos, verificamos ocorrer diferen ças nos valores "c do pelo fato da forma da cauda ser diferente, em ambos os casos: deste modo, o exemplar nacional, que possui a cauda digitada, apresentou os valores $c=53 \mathrm{e} c^{\prime}=1,1$, enquanto os da- 


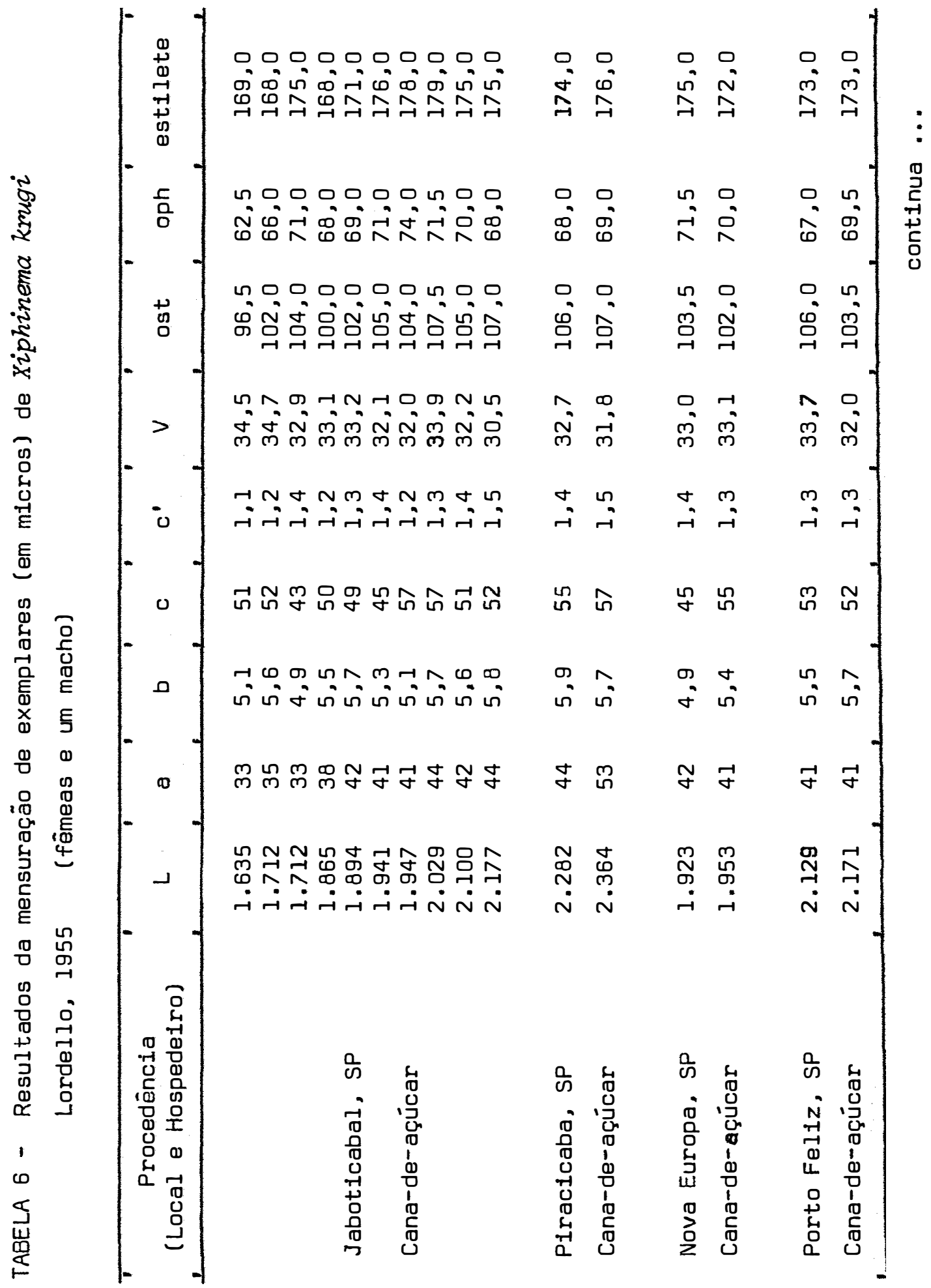




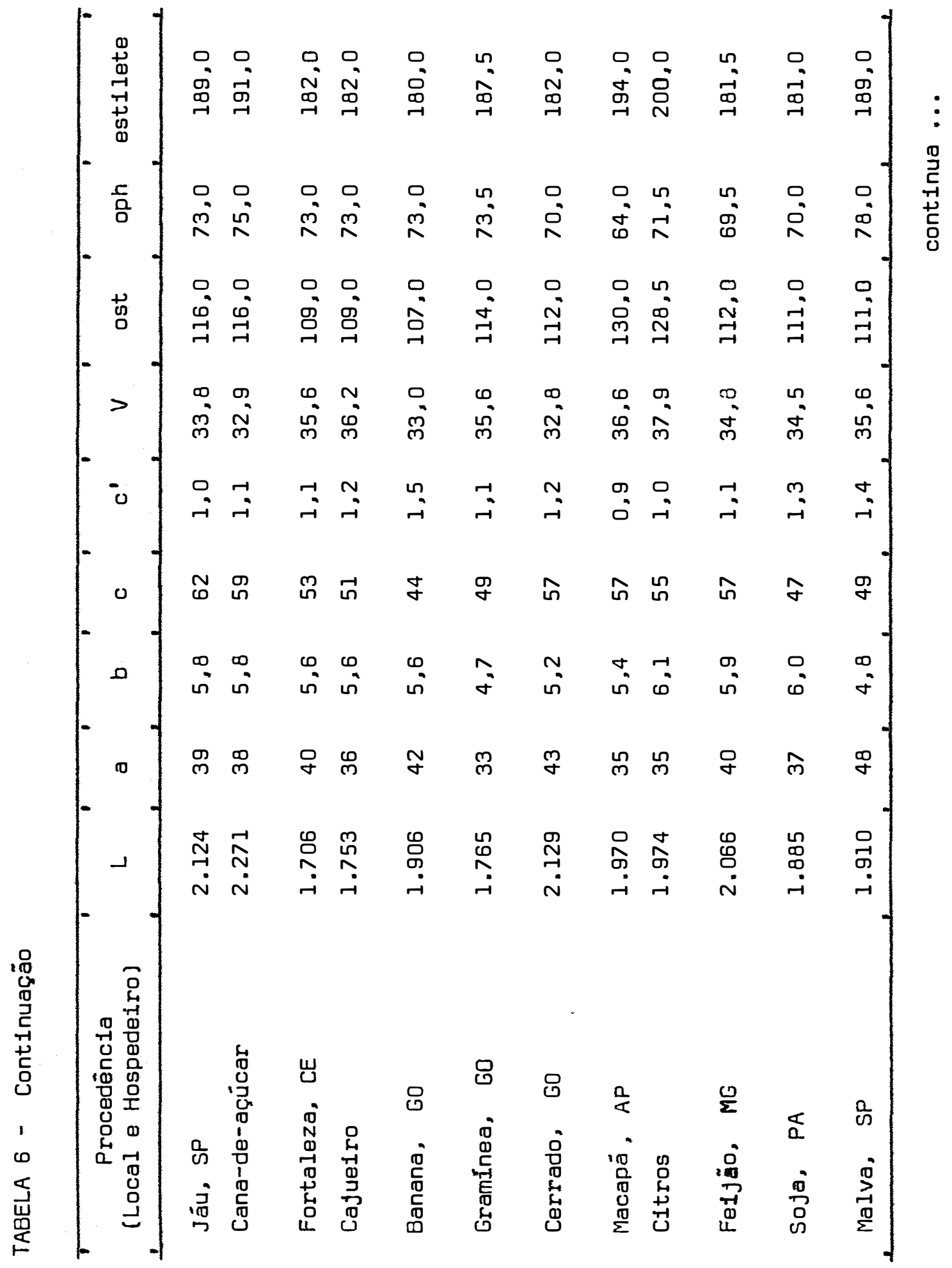




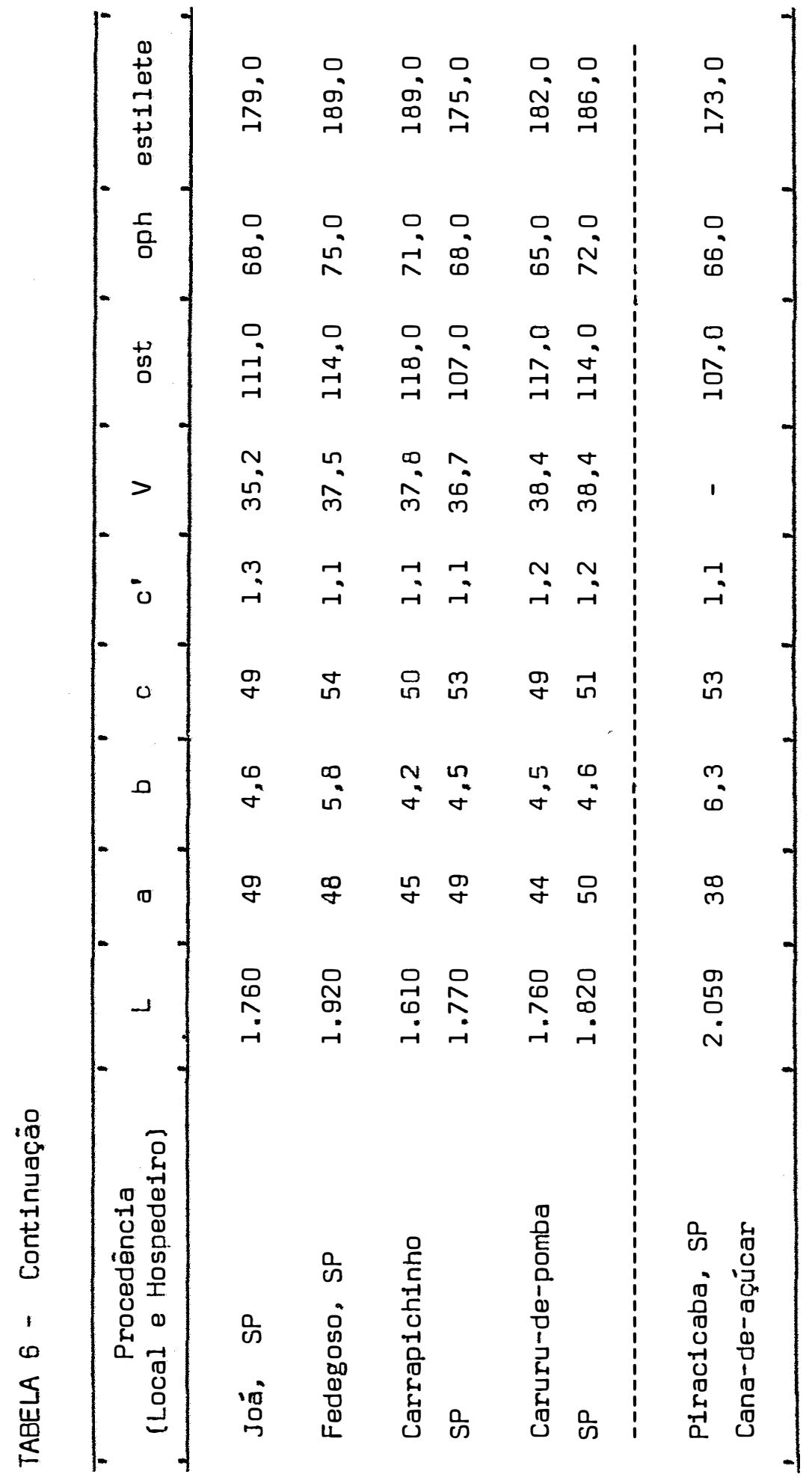


dos encontrados para o espécime originärio do Ceilão, de cauda subconoidal, foram respectivamente 64 e 0,8 . Portanto, variações na forma e dimensões da cauda também se verificam nos machos da espécie. Observamos existirem três suplementos, além do par adanal, situados a 93,122 e $147 \mu$ do ànus, respectivamente.

\section{Xiphinema setariae Luc, 1958}

X. setariae Luc, 1958. Nematologica 3: 57-62, 1958 (n.sp.)

Dimensões (em micros). Fèmeas: os resultados das mensurações dos exemplares estão contidos na Tabela 7 .

Observações: os valores que obtivemos para os espécimens na cionais mostraram-se plenamente concordantes com os da popula ção-tipo, apenas os dados relativos ao comprimento do estilete sendo ligeiramente inferiores (176-189: 192-199 $\mu)$. Ao descre

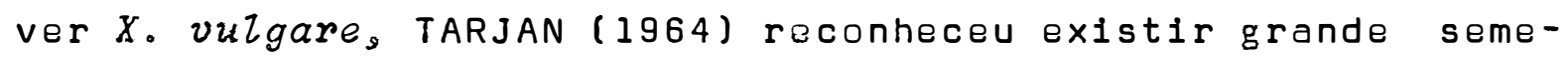
Ihança entre esta nova espécie e $X$. setariae, apresentando inclusive um estudo comparativo entre as medidas de ambas. COHN e SHER (1972) consideraram ser insignificantes as diferenças a pontadas por TARJAN e propuseram a devida sinonimia. Em verda de, os nossosvalores também concordaram com os de $\not$. vulgare, o que confirma a notável coincidéncia existente entre as carac 
teristicas morfológicas das duas espécies. Assim, sendo, pelo menos por ora, aceitamos como välida a proposição de COHN e SHER e consideramos $X$. vulgare sinónima de $X$. setariae. A espécie em questão ocorreu com bastante frequência nas amostras analisadas, sendo parasito muito polifago. Este constitui o primeiro registro de $X$. setariae wos Estados de São Pay 10 e Acre.

\section{Xiphinema surinamense toof 8 Maas, 1972}

X. surinamense Loof \& Maas, 1972. Nematologica 18:92-119 (n.sp.)

Dimensões (em micros)。Fèmeas: os dados referentes a mensuração dos exemplares estão apresentados na Tabela 8.

Observações: os valores que obtivemos para nove exemplares de fêmeas desta espécie, todos coletados na rizosfera de cana-deaçūcar, não se mostraram totalmente concordantes com a população-tipo descrita por LOOF e MAAS, com base em materiais oriun dos do Suriname. Assim, em comparação com os dados de Loof \& MAAS, encontramos valores inferiores para o comprimento do corpo $(2,0-2,4: 2,4-2,7 \mathrm{~mm})$, comprimento do odontostílio (113

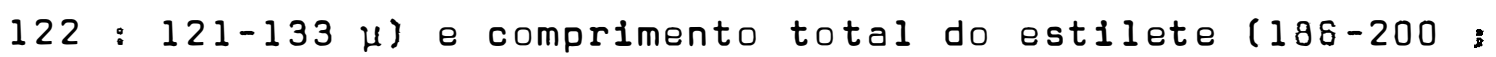
201-215 $\mu$ ). Como se observa, as diferenças varificadas foram pequenas; ademais, os próprios autores encontraram uma segunda 


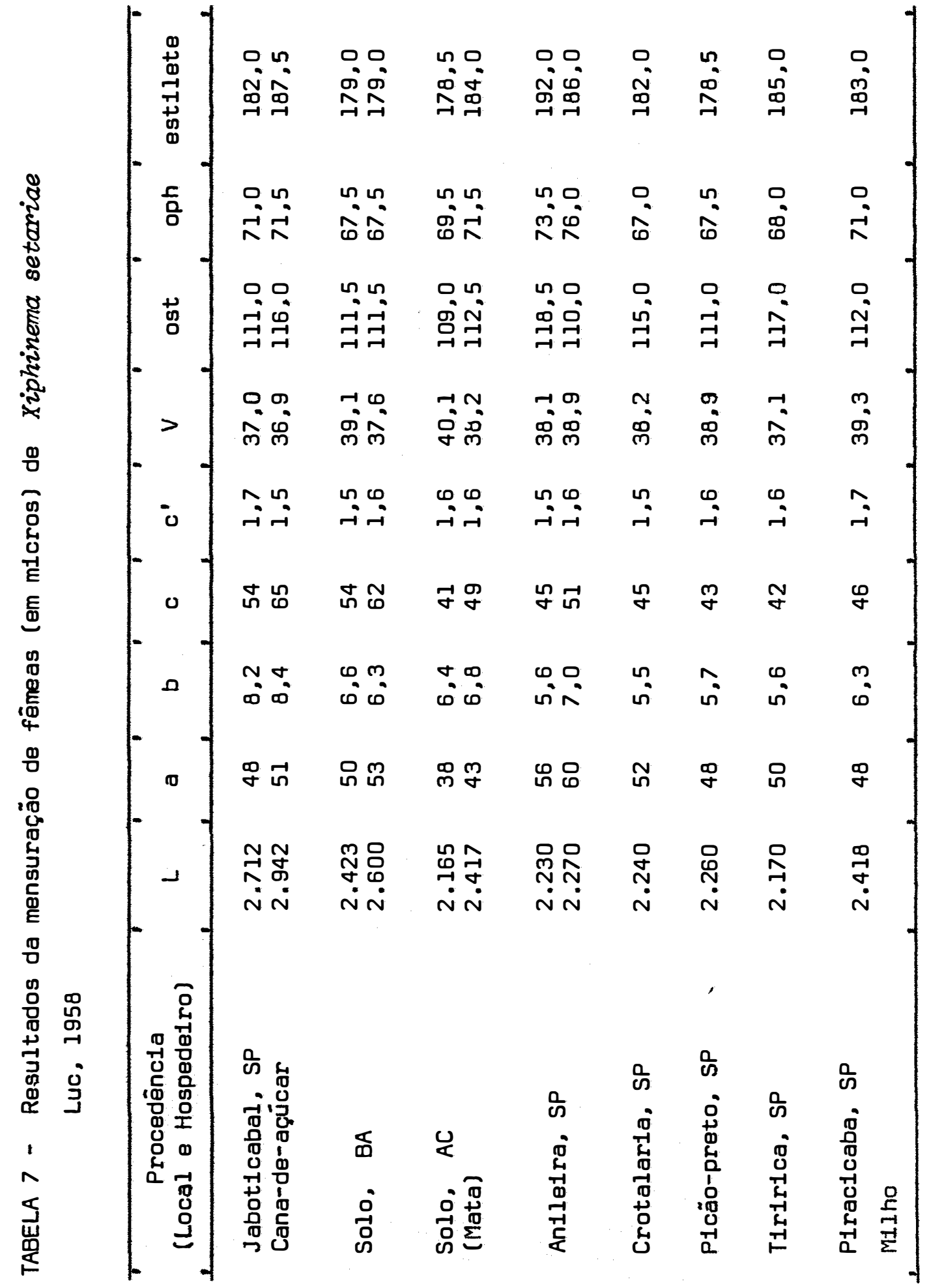




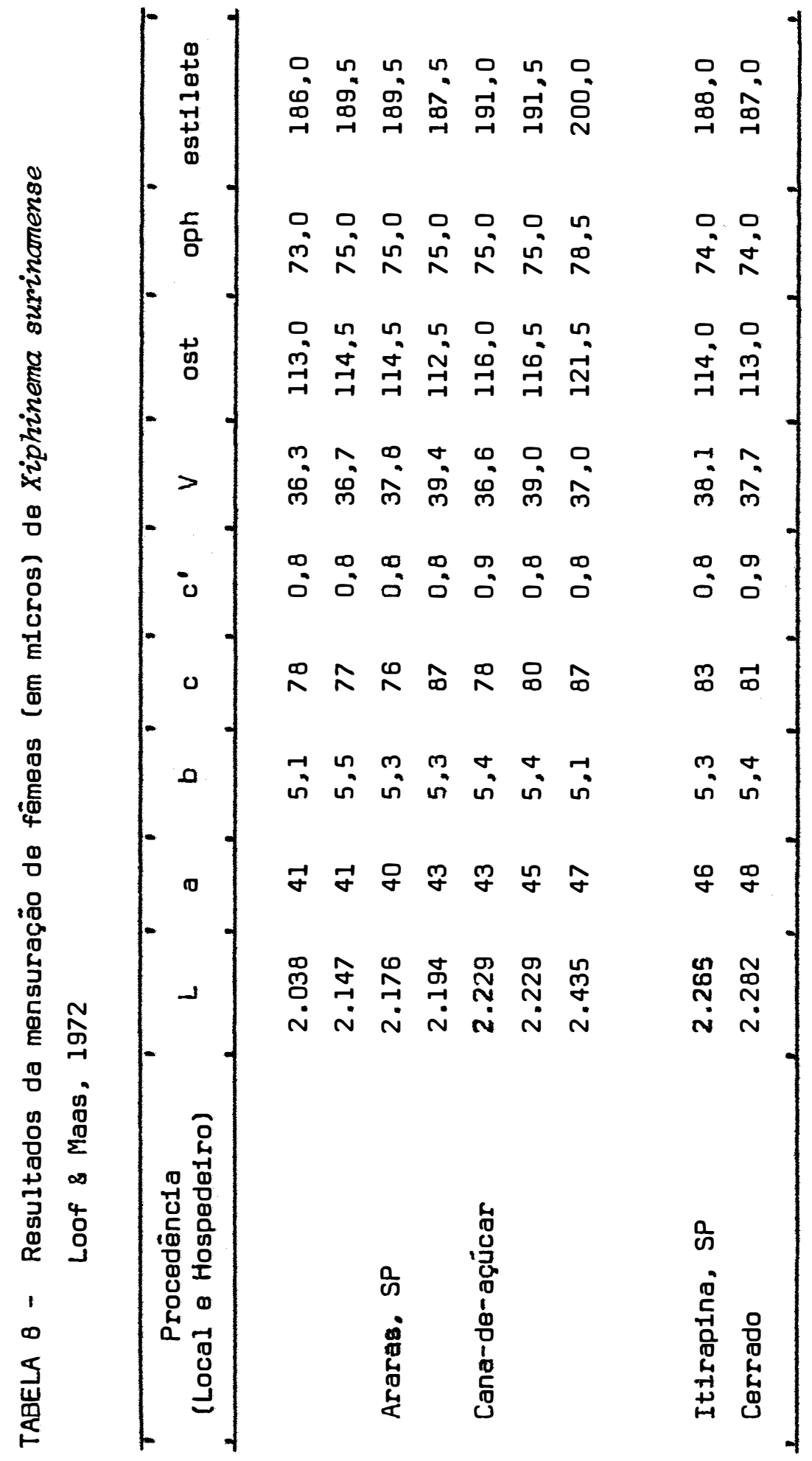


população da espëcie, também no suriname, com dimensões bem maiores que a da população tipo. admitindo então serem as va riações muito comuns em X. suriramense (LOOF e MAAS, 1972). Es ta espécie apresenta a cauda tipicamente obtusa e as fêmeas tem o ramo anterior do aparelho reprodutor incompleto, representado apenas pelo útero: todavia, ao conträrio de algumas espécies pseudomonodelfas como $X$. krugi, que possuem geralmente o ramo anterior reduzido a um útero rudimentar (saco uterino), $X$. su rinamense possui os dols úteros com desenvolvimento praticamente 1gual. Cumpre destacar que não conseguimos obter machos de $X$. surinamense, apesar de LOOF e MAAS havê-los encontrado com relativa frequência, ao descrever a espécie. Este constí tul o primeiro registro de $X$. surinamense em nosso Estado.

Xiphinema sacchari n. sp.

Medidas (em micros) - $n=5$ fêmeas: $L=2338$

$(2247-2505) ; a=37(35-40): b=6,7(6,6-7,0) ; c=45(43-$ $46): c^{\prime}=1,5-1,6 ; V=37 \%(36,5-37,5) ;$ est $=112-113 ; \mathrm{opH}=$ $76(73-77)$; estilete $=188(186-189)$. (Ver Figura I - Apêndice)

Corpo cilindráide afilando-se anteriormente à altura da cárdia e mals abruptamente na parte posterior, a partir da junção intestino-reto.

Região labial de contorno totalmente liso, separada do corpo por uma pequena depressão: lábios fundidos : anffdios largos e curtos. 
A cuticula apresenta estriação transversal quase im perceptivel, somente nitida na região caudal.

Estilete de comprimento total igual a $186-189 \mathrm{mi}-$ cros, medindo o odontostilio 112-113 micros e o odontóforo 73 77 micros; anel-guia com a estrutura posterior mais evidente situada a 108-112 micros da extremidade anterior do corpo; segue-se um tubo fino, às vezes retorcido, em cuja parede pode ser observado, com frequência, o "vestigium". Parte terminal do esófago alongada e mais expandida, medindo $108 \times 23$ micros. Os nücleos das glândulas esofagianas não foram localizados. Cárdia bastante obscura.

Fêmeas anfidelfas, com ovärios caracteristicamente reflexos. Vulva em fenda transversal alcançando $1 / 3$ da large ra do corpo. Vagina estendendo-se através do corpo além da metade da sua largura. Os ovários evidenciam 3 fileiras de oócitos na zona germinativa, enquanto na zona de crescimento os mesmos dispõem-se em filas simples. o oviduto é alongado, muito fino e termina em um esfincter; adjacente a este pon to, observa-se uma câmara uterina bem expandida e, em saguida, encontra-se o órgão $Z$, uma estrutura mais estreita, de forma oval, encerrando geralmente 2 ou 3 elementos esclerosados em seu interior. 0 útero pode expandir-se novamente mas, quando se liga a vagina, mostra-se invariavelmente estreito. Não foram observados ovos.

o pré-reto apresenta-se bem distinto em alguns exemplares, medindo 395 micros. Reto bastante evidente medin- 
do 35-40 micros.

A cauda é digitada e o apêndice digitiforme, voltado ventralmente, mede 18-20 micros. Três pares de papilas caudals säo facilmente observados lapenas dols em um espéc1menj, além de um pré-anal.

Machos: desconhecidos

Habitat-t1po: solo da rizosfera de cana-de-açúcar,

Saccharum officinarum $L$.

Localidade tipica: Usina Sta. Lidia, municipio de Ribeiräo Preto, Estado de Säo Paulo.

Espéclmens-tipo: depositados na coleçāo do autor.

Diagnose: entre as espécles que apresentam órgão 2. X. coxi Tarjan, 1964 é a que mals se assemelha a $X$. saccha$r i$, desta diferindo por apresentar malor comprimento do corpo $(3.06-4.00: 2.24-2.50 \mathrm{~mm})$, malores valores de a $(74: 37)$ e de $\underline{c}$ (65:45), além de apresentar a vulva em situaçào ma1s posterior (44:37\%). X. ebriense Luc, 1958 também apresenta a vulva em posiçäo mals posterior $(42-45: 37 \%)$ e a forma da cauda diferente. $X$. basiri siddiq1, 1959 apresenta a vulva de situaçāo equatorial (48-53:37\%) e comprimento do corpo maior $(2,70-$ $3,40: 2,40-2,50 \mathrm{~mm})$. 
Observações sobre $X$. paulistanum Carvalho. 1965

X. paulietanum fol descrita com base em trés exemplares (duas fémeas e um macho) coletados na rizosfera de jabuticabeiras - Mrciaria sp. - localizados em uma chácara nas proxi midades da cldade de São Paulo.

Esta espécle não fol, todavia, observada ao curso do presente estudo e, tampouco encontramos qualquer referéncla a mesma na literatura nacional, além da descrição original.

Em vista disso, desenvolvemos esforços no sentido de obter o material-tipo para a realizaçäo de algumas observações de fundamental importância em torno da espécie. De posse da coleção de CARVALHO, conseguimos localizar a lámina que deveria conter o holétipo e o alótipo, identificada pela legenda L.19.6.64; Xiphinema: ... I macho; l fêmea. Infel1zmente, verificamos que o material encontra-se em más condições de conservação, não sendo possivel um estudo minucioso ou mesmo, a sua recuperaçäo. 0 holótipo fol encontrado sem malores dificuldades, verificando-se estar bastante comprimido na parte médla do corpo; não houve condições para um exame das características da cauda e dos órgãos internos. 0 alótipo não fo1 observado, acreditando-se estar encoberto pelo material usado na lutagem, o qual penetrou o Interior da lamínula em uma larga faixa.

Com base no exposto e, considerando-se não existirem subsidios suficientes para a determinaçäo do local onde 
foi coletada a população-tipo, propomos que X. paulistanum seja considerada "species inquirenda". 
Chave para as espécies de Xiphinema que ocorrem no Brasil

1. Fèmeas monodelfas ou pseudomonodelfas .. 2

Fêmeas anfidelfag ............. 5

2. Fêmeas monodelfas ..............

Fêmeas pseudomonodelfas ...........4 4

3. Cauda digitada, com o apêndice digiti

forme situado em posição central; .

$c^{\prime}=1,0-1,4 ;$ estilete com 183-204

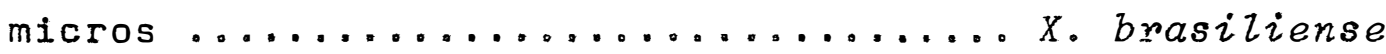

Cauda obtusa; $c^{\prime}=0,5-0,6$; estilete

com 224-238 micros ................. ensiculiferum.

4. Utero de ramo anterior parcial ou qua se totalmente atrofiado; cauda subconóide ou digitada, com o apêndice digitiforme voltado ventralmente; com primento variável de $1,6-2,1 \mathrm{~mm} \ldots . . . x$. krugi Utero de ramo anterior bem desenvolvi do: cauda obtusa; comprimento variá vel de $2,2-3,7 \mathrm{~mm} \ldots \ldots \ldots \ldots \ldots \ldots$. surinamense.

5. Orgão $z$ presente .............. 6 Órgão $z$ ausente $\ldots \ldots \ldots \ldots \ldots \ldots$ 
6. Valor $V=48-53 \%$; comprimento variável de $2,7-3,5 \mathrm{~mm} \ldots \ldots \ldots \ldots \ldots \ldots \ldots \ldots \ldots$ basiri. Valor $V=36-38 \%$; comprimento variável de $2,2-2,5 \mathrm{~mm} \ldots \ldots \ldots \ldots \ldots \ldots \ldots \ldots \ldots \ldots$ sacchari.

7. Valor $V=50-54 \% \ldots \ldots \ldots \ldots$ Valor $v=36-42 \% \ldots \ldots \ldots . \ldots . \ldots 9$

8. Cauda conóide; $c^{\prime}=0,7-0,9 \ldots \ldots \ldots$. brevicolze. Cauda conóide ou digitadas $\mathrm{c}^{\prime}=1,2-1,6$.X. americanum.

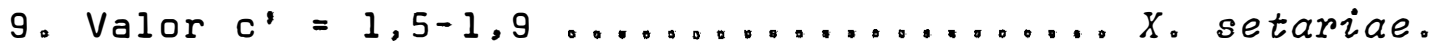
Valor c' maior que $2,3 \ldots \ldots \ldots$

10. Estilete com 150-160 micros; $c^{\prime}=2,3-$

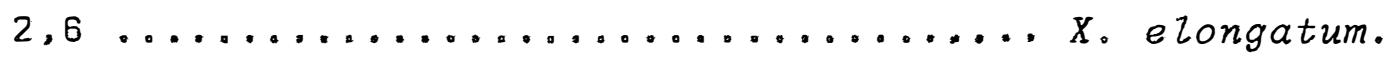
Estilete com 175-195 micros: $c^{\prime}=2,7-$

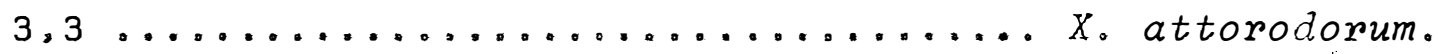


Com base nos estudos realizados, em que nove espécies du gênero Xiphinema foram identificadas, pôde-se confirmar:

a) a notável disseminação deste grupo de nematóides no Brasil, ocorrendo em praticamente todas as regiões.

b) o alto grau de polifagismo que caracteriza as suas espécies, aparecendo como parasitos muito frequentes das nossas principais culturas anuais e perenes.

c) a significação das plantas daninhas e espécies nativas como hospedeiros favoráveis aos representantes do gênero, pos sibilitando sua sobrevivência em ausência de plantas cultivadas e dificultando a elaboração de programas de controle.

d) a necessidade da realização de pesquisas, em nossas condições, que esclareçam o real participação das espécies ora identificadas na transmissão de virus altamente nocivos às plantas cultivadas de interesse econômico. 
A taxonomic study of the genus Xiphinema Cobb, 1913 in Brazil was carried out.

A historical review of the family Longidoridae and considerations about the importance of dagger nematodes as plant parasites and vectors of viruses were included.

Observations on the morphology of the family and the adopted terminology were emphasized.

Eight species of Xiphinema were identified: $X$. ame ricanum Cobb, 1913; X. attorodorum Luc, 1961; X. brasiliense Lordello, 1951; X. brevicolle Lordello \& Costa, 1961; X. elon gatum Sch. Stek. \& Teun., 1938; X. krugi Lordello, 1955: X. se tariae Luc, 1958; and, $X$. surinamense Loof \& Maas, 1972. A new species, $\not$. sacchari, is described. 
X. basiri siddiq1, 1959 and $X$. ensiculiferum lCobb, 1893) Thorne, 1937, species previously recorded in Brazil, we re not observed.

Measurements from specimens of each nominal species were given and observations on the morphology were presented and discussed.

A key for all species of Xiphinema known to occur in Brazil was given. 


\section{1 - LITERATURA CITADA}

ABOUL-EID, H. Z., 1970. Systematic notes on Longidorus and Paralongidorus. Nematologica, 16: 159-179.

CARVALHO, J. C., 1955. Plantas ornamentais parasitadas por espécles do gênero Xiphinema. Rev. Inst. Adolfo Lutz, Säo Paulo 15: 180-185.

CARVAlHo, J.C., 1962a. Observações em torno de duas espécles de Xiphinema. Arq. Inst. Blológ1co, Säo Paulo 29: $217-222$.

CARVALHO, J.C., 1962b. Xiphinema itanhaense n. sp. (Nematoda, Dorylaimidae). Arq. Inst. Biológico, São Paulo 29: 223-225.

CARVALHO, J. C., 1965. Xiphinema paulistanum uma nova espé cie de nemató1de. Arq. Inst. Blológlco, São Paulo 32: 77-79. 
CHITWOOD, B. G., 1957. A new species of Xiphinemelza Loos, 1950 (Nematoda) from florida. Proc. helminth. Soc. Washo. 24: $53-56$.

COBB, N. A., 1913. New nematode genera found Inhabiting fresh water and nonbrackish soils. ․ Wash. Acad. Sci. 3 : 432444 .

COHN, E., 1969. The occurrence and distribution of species of Xiphinema and Longidorus in Israel. Nematologica, 15: $179-192$.

COHN, E., 1970. Observations on the feeding and simptomatology of Xiphinema and Longidorus on selected host roots. J. Nematology 2 : $167-173$.

COHN, E. e ORION, 1970. The pathological effect of represen tative Xiphinema and Longidorus species on selected host plants. Nematologica 16: $423-428$.

COHN, E。: E. TANNE e F.E.NITZANY, 1970. Xiphinema italiae, a new vector of grapevine fanleaf virus. Phytopathology 60: $181-182$.

COHN, E。 e S. A. SHER, 1972. A contribution to the taxonomy of the genus Xiphinema Cobb, 1913. J. Nematology 4 : 3665 .

COOMANS, A., 1965. Structure of the female gonads in members of the Dorylaimina. Nematologica 10: 601-622.

OALMASSO, A. 1969. Etude anatomique et taxonomique des gen res Xiphinema, Longidorus et Paralongidorus (Nematoda: Dorylaimidae). Mém. Mus. natn. Hist. nat.. Paris, Sér. A 2001. 6I: 33-82. 
DALMASSO, A.; D. BOUBALS; M. BONCIOVANNI e R. PISTRE, 1972. Oistribution of nematode vectors of fanleaf virus in French Mediterranean vineyards. Progrés. Agricole et Viticole 19 $456-462$.

FREDERICK, J. J. e A. C. TARJAN, 1974. Morphological variation in Xiphinema krugi Lordello, 1955. Proc. Soll and Crop. Science Society of Florida 34: 181-185.

s FRITZCHE, R. e H. KEGLER, 1968. Nematoden als vektoren von viruskranktheiten der Obstgewachse. Tag. Ber. dt. Akad. Landw. Wiss. Berlin 97: 289-295.

GOODEY, J. B. e B. J. HOOPER, 1963. The nerve rings of Longidorus and Xiphinema. Nematologica 9: 303-304.

GRIFFIN, G. O. e A. H. EPSTEIN, 1964. Association of dagger nematodes Xiphinema americanum with stunting and winter kill of ornamental spruce. Phytopathology 54: 177-180.

HEWITT, W. B., D. J. RASKI e A. C. GOHEEN, 1958. Nematode vector of soil-borne fanleaf virus of grapevines. Phytopathology 48: 586-595.

HEYNS, J., 1966a. Further studies on South African Longidoridae (Nematoda). S. Afr. J. agric. Sc1. 9: 927-944.

HEYNS, J., 1966b. Paralongidorus capensis n. sp. and Longidorus bezondiroides $n$. sp. with a note on $L$. taniwha clark, 1963 (Nematoda. Longidoridae). Nematologica 12: 568-574.

HEYMS, J., 1974a. The genus Xiphinema in South Africa I. $X$. americanum - group (Nematoda: Dorylaimida). Phytophylactica $\underline{6}$ : $157-164$. 
HEYNS, J., 1974a. The genus Xiphinema in South Africa II. X. amexicanum - group (Nematoda: Dorylaimida). PhytophyIactica 6: $\quad-\ldots 249-264$.

HOOPER, D. J. e J.F. SOUTHEY, 1973. The identification and biology of Longidorus, Paralongidorus e Xiphinema species. found in the British Isles with observations on the oesophageal ultrastructure of some species. Rothamsted Experimental Station, Rothamsted, $62 \mathrm{p}$. (manual datilografado).

HUANG, C. S. e F. P. CUPERTINO, 1976. Nematóides fitoparasi tas em áreas cultivadas do Distrito Federal e Goiás, Bra sil. Resumos do IX Congresso Brasileiro de Fitopatologia, Campinas, p. 19-20.

HUANG, C. S.; E. P. HERINGER e F. P. CUPERTINo, 1976. Nematóides de estilete do cerrado virgem no Brasil Central. Resumos do IX Congresso Brasileiro de Fitopatologia, Campi nas, p. 20-21.

JENKINS, W. R. e D. P. TAYLOR, 1967. Plant Nematology. Reinhold Publishing Corporation (eds.), New York, $270 \mathrm{P}$.

KHAN, S. H. e S. AHMAD, 1975. Longidoroidea (Thorne, 1935) n. rank. (Nematoda: Dorylaimina) with the description of Xiphinema neoamericanum $n$. sp. from India and proposal of a new name for $X$. americanum sensu Carvalho (1956) non Cobb, 1913. Nematologia Mediterranea 3: 23-28.

KIRKPATRICK, J. D.: S. D. VanGUNDY E J.P. MARTIN, 1965. EI fects of Xiphinema index on growth and abscission in Carig nane grape. Nematologica 11: 41.

LAMBERTI, F. e A. C. TARJAN, 1974. Xiphinema costaricense n. sp. (Longidoridae, Nematoda) a new species of dagger nematode from Costa Rica. Nematologia Mediterranea 2: 1-11. 
LIMA, J. A.; M. MENESES, M.Q. KARAN E O.F. G. MARTINS, 1975 . Gèneros de nematóides fitopatogènicos isolados da rizosfera do cajueiro Anacardium occidentale L. Fitossanidade, Fortaleza, 1: $32-34$.

S LISKHOVA, M. e M. SABOVA, 1973. The occurrence of ecto-parasitic phytonematodes $X$. brevicolle in the vineyards of East Slovakia。 Biologia Bratislava, 28: $351-354$.

LOOF, P. A. A. e A. COOMANS, 1972. The oesophageal gland nuclei of Longidoridae (Dorylaimida). Nematologica 18: 213233.

LOOF, P. A. A. E P.W. T. MAAS, 1972. The genus Xiphinema (Dorylaimida) in Surinam. Nematologica 18: 92-119.

Loos, C. A., 1949. Notes on free-living and plant-parasitic nematodes from Ceylon. J. Zool. Soc. India 1: 30-36.

Loos, C. A., 1950. Xiphinemelza nom. nov. A change of name for Taprobanus Loos, 1949 (Nematoda: Dorylaimidae). J. 2001. Soc. India 2: 149 .

LORDELLO, L. G. E., 195la. Xiphinema brasiliense, nova espécie de nematóide do Brasil, parasita de Solanum tuberosum L. Bragantia, Campinas, 11: 87-90.

LORDELLO, L. G. E., 1951b. Xiphinema campinense, nova espé cie (Nematoda, Dorylaimidae). Bragantia, Campinas, 11: 313 316 .

LORDELLO, L. G. E., 1953. Contribuição ao conhecimento dos. nematóides do solo de algumas regiões do Estado de São Pau10. ESALQ/USP, Piracicaba, $76 \mathrm{p}$. (Tese de Doutoramento). 
LORDELLO, L.G. E., 1955. Xiphinema krugi n. sp. (Nematoda: Dorylaimidael from Brazil with a key to the species of $X i$ phinema. Proc. helminth. Soc. Wash. 22: 36-21.

LORDELLo, L. G. E., 1965. Contribuição para o conhecimento dos nematóides brasileiros da família Dorylaimidae. ESALQ USP, Piracicaba, $68 \mathrm{p}$. (Tese de Livre-Docència).

LORDELLO, L. G. E. e H. V. ARRUDA, 1956. Nematóides parasitando guandu. Bragantia, Campinas, 16, nota $n^{8} 2$ : V-VII.

LORDELlo, L. G. E. e A. P. L. ZAMITH, 1960. Sobre os nema tóides que parasitam o pessegueiro. Anais da E. S. A. "Luiz de Queiroz", Piracicaba 17: 361-364.

LORDELlo, L. G. E. e C. P. COSTA, l961. A new nematode para site of coffee roots in Brazil. Revista Brasil. Biologia, Rio de Janeiro, 21: 363-366.

LORDELLO, L. G. E., F。 CARNEIRO, E。 K. REBEL, J.A. GUIDOLIN e R.R. A. LORDELLO, 1974. Identificação de nematóides em cafezais do Estado do Paraná. Soc. Brasil. Nematol. Pi racicaba, publ. $n^{8}$ I: $16-24$.

LUC, M., 1958. Xiphinema de l'ouest africain: Oescription de cinq nouvelles espèces. Nematologica 3 : 57-72.

LUC, M., 1961. Xiphinema de l'ouest africain (Nematoda: Dorylaimoidea). Oeuxième note. Nematologica 6: 144-154.

5 MAN, J.C. de, 1884. Oie frei in der reinen Erde und im sussen Wasser lebenden Nematoden nederlandischen Fauna. Eine systematische faunistische Monorgraphie. J. Brill, Leiden, $206 \mathrm{p}$. 
MCELROY, F. O., 1972. Studies on the host range of Xiphine-ma bakeri and its pathogenicity to raspberry. J. Nematology 4 : $16-22$.

MEYL, A. H., 1961. Die freilebenden Erd-und Suesswasser nematoden (Fadenuwuermer). In: Die Tierwelt Mitteleuropas. Quelle \& Meyer (eds,), Leipzig, $273 \mathrm{p}$.

MILNE, D。L., E. A. VILLIERS e L. C. HOLTZHAUSEN, 1971. Lit chi tree decline caused by nematodes. Phytophylactica 3 : 37-44.

MONTEIRO, A. R., 1970. Oorylaimoidea dos cafezais paulistas. ESALQ/USP, Piracicaba, $137 \mathrm{p}$. (Tese de Doutaramento).

MONTEIRO, A. R., 1975. Sistemática atual de Actinolaimoidea (Nemata, Oorylaimida) e estudo de algumas espécies brasi leiras. ESALQ/USP, Piracicaba, 85 p. (Tese de Livre-Do cência).

MONTEIRO, A. R., 1976. Xiphidorus yepesara n. gen., n. sp. (Nemata, Longidoridae) from Brazil. Nematologia Mediterrânea 4 : 1-6.

NORTON, D. C.. 1967. Xiphinema americanum as a factor in un thriftiness of re clover. Phytopathology 57: 1390-1391.

NOVARETTI, W. R. T., A. O. ROCCIA, A. R. MONTEIRO E L. G. E. LORDELLO, 1974. Contribuição ao estudo dos nematóides que parasitam a cana-de-açúcar em São Paulo. Soc. Bra sil. Nematol.. Piracicaba, publ. n8 1: 27-32.

PERRY, V.G., 1958. Parasitism of two species of dagger nematodes ( $X$. americanum and $X$. chambersi) to strawberry. Phytopathology 48: 420-423. 
RUEHLE, J. L., 1972. Pathogenicity of $X$. chambersi on sweet gum. Phytopathology 62: 33з-336.

SCHINDLER, A. F., 1957. Parasitism and pathogenicity of Xiphinema diversicaudatum, an ectoparasitic nematode. Nemato. logica 2 : $25-31$

SCHUURMANS STEKHOVEN, J. H. e R. J. H. TEUNISSEN, 1938. Nematodes libres terrestres. Expl. Parc. Nat. Albert. Inst. Parcs. Nat. Congo Belge. Bruxelas 22, 229 p.

SIDDIQI, M. R., 1965. Longidorus nirulai n. sp. a parasite of potato plants in shillong. India, with a key to species of Longidorus. Proc. helminth. Soc. Wash. 32: 95-99.

SIDDIQI, M. R., D. J. HOOPER e E. KHAN, 1963. A new nematode genus Paralongidorus (Nematoda: Dorylaimoidea) with des criptions of two new species and observations on Paralongidorus citri (Siddiqi. 1959) n. comb. Nematologica 9: 714.

SHARMA, R. D., 1971. Nematódios associados com o cacaueiro e seringueira na Bahia. Revista Theobroma, Ilhéus, $1: 43$ 45 .

SHARMA, R. O.. 1976. Nematodes of cocoa region of Espirito Santo. II - Nematodes associated with field crops and forest trees. III Congresso Brasileiro de Entomologia, Ma ceió, 7 p. (resumo datilografado).

SHARMA, R. O. e P. A. A. LOOF, 1972. Nematodes associated with different plants at the Centro de Pesquisas do Cacau, Bahia. Revista Theobroma, Ilhéus, 2 (4): 38-43. 
SHARMA, R. D. e P. A. A. LOOF, 1973a. Nematodes of the cocoa region of Bahia, Brazil. I. Plant parasitic and free living nematodes associated with rubber (Hevea brasiliensis Muell. Arg.). Revista Theobroma, Ilhéus, 3 (1): $36-$ 41.

SHARMA, R. D。 e P. A. A. LOOF, 1973b. Novo tipo de enfermidade da goiabeira causada por nematóides na Bahia. Cacau, Atualidades, Ilhéus, 10 (1): 20-21.

SHARMA, R。D。e P.A. A. LOOF, 1974a. Nematodes of the cocoa region of Bahia, Brazil III. Plant parasitic and free living nematodes in the rizospheres of different plant spe cies. Revista Theobroma. Ilhéus, 4 (1): 39-43.

SHARMA, R. D. e P.A. A. LOOF, 1974b. Nematodes of the cocoa region of Bahia, Brazil IV. Nematodes in the rizos pheres of pepper ( Piper nigrum L.) and clove (Eugenia caryophyzzata Thunb.). Revista Theobroma, Ilhéus, 4 (3): $26-32$.

SHARMA, R. D. e S.A. SHER, 1973a. Nematodes associated with banana in Bahia, Brazil. Ciêncla e Cultura, Säo Pau 10, 25: 665-668.

SHARMA, R. O. e S. A. SHER, 1973b. Nematodes associated with citrus in Bahia, Brazil. Ciência e Cultura, São Pau $10,25: 668-672$.

SHARMA, R. D. e S. A. SHER, 1973c. Nematodes of the cocoa region of Bahla, Brazil II - Occurrence and distribution of plant parasitic nematodes associated with cocoa (Theobroma cacao L.). Revista Theobroma, Ilhéus, 3 (I): 1724. 
SHARMA, R. D. e S. A. SHER, 1974. Nematódios da região ca caueira do Esplrito Santo, Brazil. I - Nematódios associados ao cacaueiro (Theobroma cacao L.). Revista Theobroma, Ilhëus, 4 (4): 26-31.

SOUTHEY, J. F. e M. LUC, 1973. Redefinition of Xiphinema en siculiferum (Cobb, 1893) Thorne, 1937 and description of Xiphinema loosi n. sp. and Xiphinema hygrophilum n. sp. (Nematoda, Dorylaimoidea). Nematologica 19: 293-307.

STEINER, G., 1951. Curso de Nematologia Geral de Plantas. Instituto Agronómico do Estado de São Paulo, Campinas, 22 p. ilustrado.

5 STURHAN, D. von, 1963. Allometrische untersuchungen an Longidoriden (Nematoda: Dorylaimoidea). $\quad \underline{z}$ Morph. Okol. Tie re, Berlim, 53: 39-60.

TARJAN, A. C., 1964. Two new american dagger nematodes (Xiphinema: Dorylaimidae) associated with citrus, with com ments on the variability of $X$. bakeri Williams, 196l. J. helminth. Soc. Wash. 31: 65-76.

TARJAN, A. C., 1969. Variation within the Xiphinema america num group (Nematoda: Longidoridae). Nematologica 15: 241 252.

TARJAN, A. C. e M. LUC, 1963. Observations on Xiphinema insigne Loos, 1949 and Xiphinema elongatum Sch. Stek. \& Teun.. 1938 (Nematoda: Dorylaimidae). Nematologica 9: 163-172.

THORNE, G., 1935. Notes on free living and plant parasitic nematodes. Proc. helminth. Soc. Wash. 2: 96-98. 
THORNE, G., 1939. Monograph of the nematodes of the super family Dorylaimoidea. Capita Zoologica 8 , 5, $261 \mathrm{p}$.

WRIGHT, K. A., 1965. The histology of the oesophageal re gion of Xiphinema index Thorne \& Allen, 1950, as seen with electron microscope. Canad. J. 2001. 43: 689-700.

$\$$ - As referèncias assinaladas não foram consultadas no original. 
73.

12 - A P E D I C E 


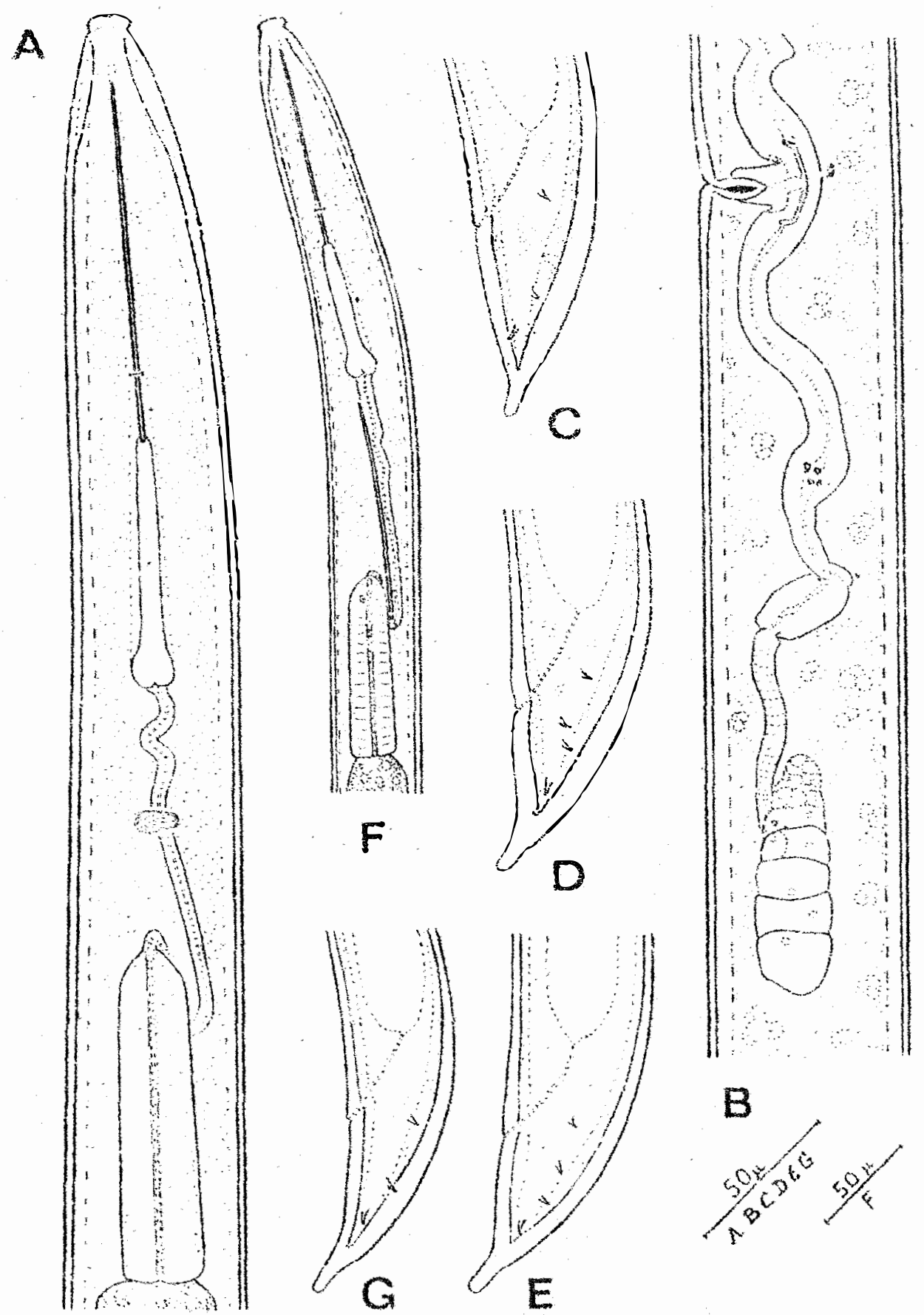

ig. A-G : Kiphinema sacchari sp. n. - A : regiäo esofagiana do femea ; B : ramo posterior do aparelho reprodutor feminino : C-E : regiēo posterior das fêmeas : $F$ : região esofagiana da larva ; G : regiäo posterior da larva. 

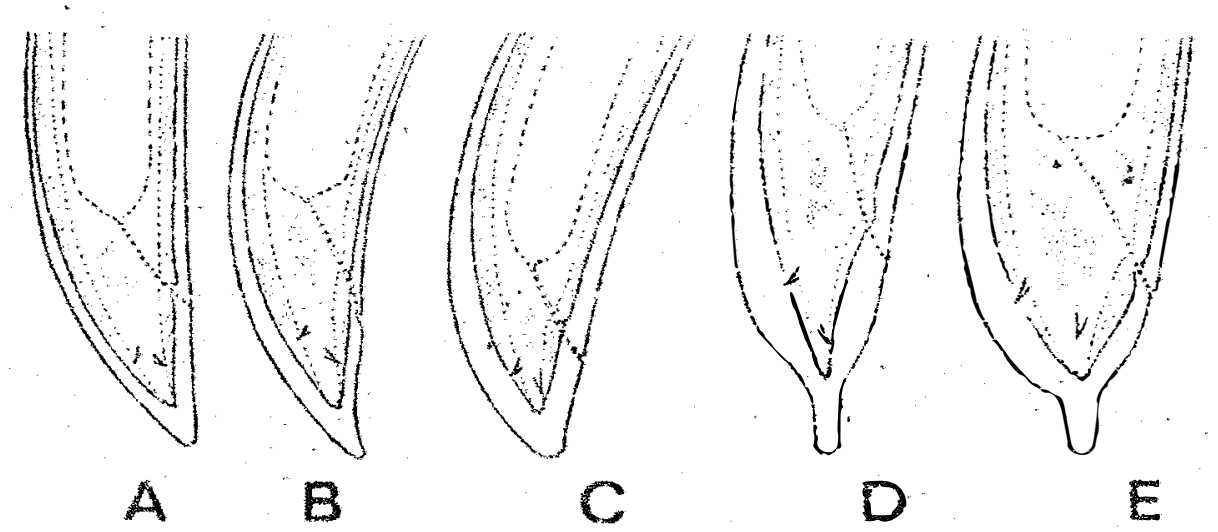

C

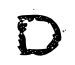

E

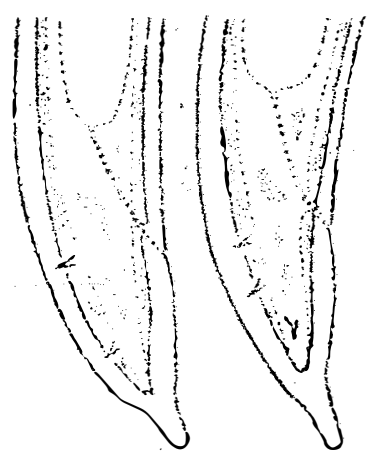

F

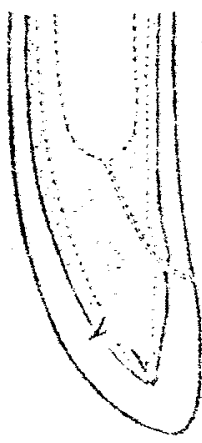

K
G

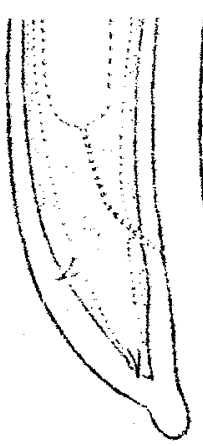

L
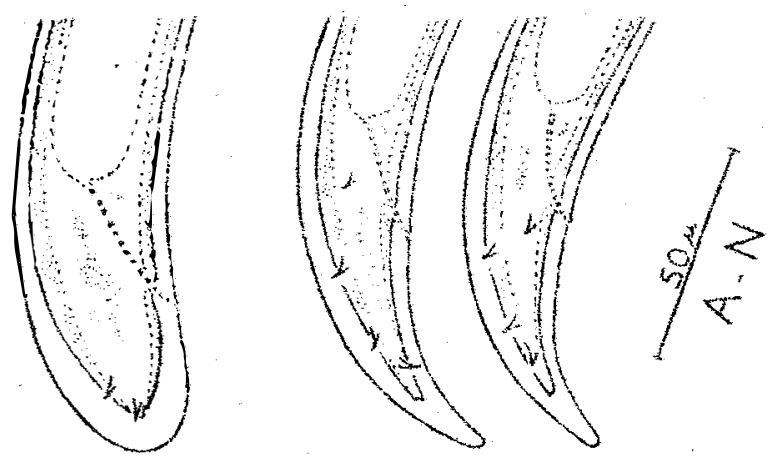

$H$

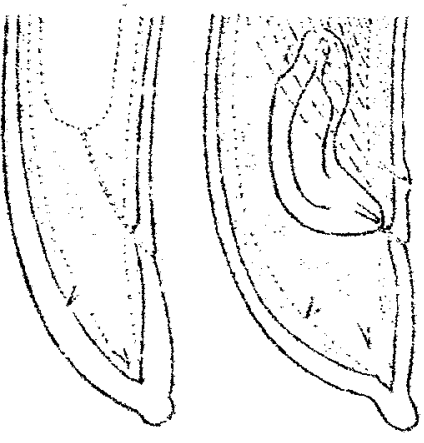

N

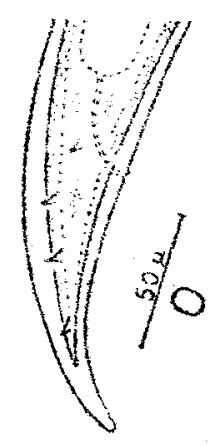

0

Fig. A-O : Regtäo posierior das espéctes brasiletras do Gênero Xiphine ma - A-B : $X$. anemicanm Cobb. $1913: \mathrm{C}: X$. brevicolLe Lordello \& Costa, 1961 , D-E : X. Brasiliense Lordello, $1961 ; F-G: X$. setariae Luc, $1958 ; H: X$. surinamense Loof \& Mass, $2972 ; I-J$ : $X$. elongatzon Schuumans Stekho -. ven \& Teunissen, $1938, K-N: X$. Kmugi Lorde1lo, 1955 $(N=$ macho $) ; 0: X$. attorodomon Lue, 1961 . 